\title{
Binds and Bounds of Communion: Effects of Interpersonal Values on Assumed Similarity of Self and Others
}

\author{
Kenneth D. Locke, Traci Craig, Kyoung-Deok Baik, and Krutika Gohil \\ University of Idaho
}

\begin{abstract}
Assumed similarity refers to ascribing similar attributes to the self and others. Because self-other similarity facilitates communion, people who value communion should be prone to assume self-other similarity; but because self-other similarity also evokes obligation, they may be prone to assume similarity only with others with whom they are or would feel comfortable being interconnected. We tested these hypotheses in 5 studies (total $N=1,709$ ). In Study 1, students indicated their political preferences and estimated other students' preferences. In Studies 2-5, students described their personality and the personalities of the following targets: actual or imagined romantic partners in Study 2; ingroup members (students from the respondents' university) and outgroup members (students from a foreign university) in Studies 3-4; and specific liked and disliked others in Study 5. As hypothesized, people with stronger communal values were more likely to assume self-other similarity with liked others, romantic partners, and ingroup members, but not with disliked others and outgroup members. These effects replicated across different cultures (India, Korea, and the United States) and remained significant when controlling for self-esteem, national identification, and attribute desirability. Although people who valued communion tended to depict themselves and liked and ingroup others in relatively normative (typical) ways, which partially explained assumptions of similarity and indicated that those assumptions were to some extent accurate, communal values continued to predict distinctive self-other similarity or "false consensus" even after controlling for the normative prevalence of attributes.
\end{abstract}

Keywords: assumed similarity, interpersonal values, communion, false consensus

People tend to predict that the attributes (e.g., attitudes, beliefs, experiences, behaviors, and traits) of others will be similar to their own attributes. This phenomenon has been studied extensively in a variety of settings, and with a multiplicity of attributes and targets (Krueger, 2000; Robbins \& Krueger, 2005). The basic phenomenon has also been approached from diverse theoretical perspectives, and accordingly has received many different names, including assumed similarity (e.g., Cronbach, 1955; Human \& Biesanz, 2011; Kenny, 1994), attributive projection (e.g., Holmes, 1968, 1978), social projection (e.g., Krueger, 2007), false consensus (e.g., Marks \& Miller, 1987; Ross, Greene, \& House, 1977), the self-based heuristic (Ready, Clark, Watson, \& Westerhouse, 2000; Weller \& Watson, 2009), and self-anchoring (e.g., Cadinu \& Rothbart, 1996; Otten \& Wentura, 2001). In the present article, we

This article was published Online First July 23, 2012.

Kenneth D. Locke, Traci Craig, Kyoung-Deok Baik, and Krutika Gohil, Department of Psychology, University of Idaho.

Kyoung-Deok Baik is now at the Department of Psychology, Bowling Green State University.

Ilhoon Jung, Chanjong Baik, Seungil Baek, Daniel Choi, Sanghoon Choi, Jiyun lim, Jeonghee Yun, Kyuchul Cho, Misook Um, Yoohan Ko, and Hunman Lim helped us to translate materials into Korean and recruit participants in Korea. Girish Puranik, Jaydev Bhola, Sharon Writer, and Viral Shah helped us to translate materials into Gujarati and recruit participants in India.

Correspondence concerning this article should be addressed to Kenneth D. Locke, Department of Psychology, University of Idaho, Moscow, ID 83844. E-mail: klocke@uidaho.edu use the term assumed similarity because it does not imply any particular mechanism or bias and is favored by previous researchers who share our analytic approach.

Researchers have been interested in assumed similarity for at least two reasons. First, by showing how representations of the self and representations of others are linked, assumed similarity reveals crucial joists in the architecture of social cognition. Second, assumed similarity influences social relations. A voluminous literature affirms that assumed self-other similarity predicts feelings of attraction and connection (Byrne, 1971; Montoya, Horton, \& Kirchner, 2008), and increasing depth of friendship over time (Selfhout, Denissen, Branje, \& Meeus, 2009). When strangers are enmeshed in an interdependent task or social dilemma, assumed similarity can improve their cooperation and performance (Krivonos, Byrne, \& Friedrich, 1976; Orbell \& Dawes, 1991), and in romantic couples, assumed similarity can enhance feelings of being understood and relationship satisfaction (Murray, Holmes, Bellavia, Griffin, \& Dolderman, 2002). The sense of oneself overlapping with another person can increase empathy and altruism toward that person (Cialdini, Brown, Lewis, Luce, \& Neuberg, 1997). Conversely, defining others as different—or in a distinct category-from the self can contribute to dehumanizing and discriminating against them (Krueger, 2007).

Although people appear generally inclined to assume similarity between the self and others (Krueger, 2000), there may also be individual differences in the propensity to assume self-other similarity. Neither cognitive ability nor reasoning biases predict assumed similarity (Stanovich \& West, 1998); however, there are both theoretical and empirical bases for expecting interpersonal 
values - particularly the value people place on experiencing communion with others - to predict assumed similarity. Investigating that possibility was the central aim of the present article.

\section{Communal Values}

Two fundamental dimensions of interpersonal behavior and motivation are agency (dominance, control) and communion (friendliness, warmth) (Horowitz et al., 2006). Factor analyses show that these two dimensions account for a large proportion of the variance in ratings of interpersonal dispositions (Foa, 1961; Wiggins, 1979), including interpersonal values (Locke, 2000). Compared with people with weak agentic values, those with strong agentic values place more importance on having power and less importance on avoiding conflict in interpersonal situations. Compared with people with weak communal values, those with strong communal values place more importance on experiencing mutual support and connection and less importance on guarding or protecting themselves in their interpersonal relationships.

The dimensions of agency and communion constitute the basic axes of the interpersonal circumplex, a popular model for conceptualizing and assessing interpersonal dispositions (Fournier, Moskowitz, \& Zuroff, 2011; Locke, 2011). In the first book to articulate and explore the explanatory power of the interpersonal circumplex, Leary (1957) offered numerous insightful observations about individuals whose predominant interpersonal dispositions were in the communal octant of the circumplex. He described individuals with moderate levels of communal tendencies as "more likely to cooperate, to go along with the conventional pattern ... less likely to emphasize a unique, original, or highly controversial point of view" (p. 303). He described individuals with extreme communal tendencies as "so committed to conventional responses that they forfeit originality and individuality. . . They seem to fear being individuals" (pp. 304-305). In short, Leary suggested that communal individuals prefer to be similar to rather than distinct from others.

Subsequent research has supported Leary's (1957) observations. Mikulincer, Orbach, and Iavnieli (1998) found that assumed selfother similarity is stronger for people with an anxious-ambivalent attachment style (who fret about being loved and not rejected) but weaker for people with an avoidant attachment style (who do not emphasize communal goals in their relationships; Locke, 2008). Locke and Christensen (2007) found that undergraduates with stronger communal values were more likely to ascribe the same personality traits to both the self and a close friend. Correlations between self-ratings and friend ratings were also stronger for people who scored higher on "relational-independent selfconstrual" (a trait positively correlated with communal values) and weaker for people who scored higher on Machiavellianism (a trait negatively correlated with communal values) (Cross, Morris, \& Gore, 2002; Locke \& Christensen, 2007). Finally, Morrison and Matthes (2011) found that individuals' need to belong predicted greater assumed consensus for opinions about personally important social issues and was reduced by learning that personally important opinions were commonly shared. The latter result suggests that assumed similarity fulfills needs for belonging. More generally, believing that others share our attributes (e.g., beliefs, traits, preferences) may help affirm that our attributes are normal, correct, or appropriate and that, accordingly, we are accepted, supported, and liked members of a larger group (Marks \& Miller, 1987). If so, then perceived similarity may be especially attractive to people who value being supported and embraced. Indeed, studies of naturally occurring social comparisons show that people with stronger communal values do respond more positively to noticing similarities between themselves and others (Locke, 2003). On the basis of the preceding discussion, we hypothesized that communal values will be positively associated with assumed similarity.

\section{Communal Binds and Boundaries}

Cooperative relationships create opportunities to achieve goals that would be difficult or impossible to achieve independently; however, cooperative relationships can involve costly expenditures of resources and ongoing social obligations (Kurzban \& Leary, 2001). Because our resources (e.g., time, wealth, emotional support) are limited, they cannot be shared with everyone. In short, communion has bounds because the binds of communion have costs.

Therefore, evolutionary psychology predicts that psychological adaptations to form cooperative relationships evolved along with complementary adaptations to discriminate between who to include and who to exclude from such relationships (Kurzban \& Leary, 2001). Specifically, cooperation is most beneficial when limited to kin and people who will reciprocate benefits received. Consequently, cues that have historically predicted kinship and reciprocal altruism - such as sharing similarities and group memberships - should evoke cooperation. Moreover, people are most inclined to identify with individuals or groups with whom they share attributes that are distinctive rather than common (Leonardelli, Pickett, \& Brewer, 2010; Miller, Turnbull, \& McFarland, 1988); attributes that fail to distinguish among people or groups will fail to clarify to whom one owes and from whom one can expect loyalty. The prototypical image of communion is a circle of people holding hands because it conveys both communion and closure; by binding together those inside, the circle excludes those outside.

If assumed similarity evokes communion and people seek to limit communion, then people should limit assumed similarity. Indeed, research confirms that people generally do assume more similarity with some individuals than others. One predictor is sentiment toward the target: People assume greater similarity with individuals who they already feel attracted and close to, and with whom they have experienced or anticipate experiencing cooperation and affection rather than competition and conflict (Human \& Biesanz, 2011; Toma, Yzerbyt, \& Corneille, 2010; Weller \& Watson, 2009). Thus, although assumed similarity may facilitate liking, liking may also facilitate assumed similarity (Morry, 2005). Another predictor of assumed similarity is group membership: People tend to assume greater similarity with ingroup members (with whom they share a group membership) than with outgroup members (DiDonato, Ullrich, \& Krueger, 2011; Otten, 2002; Robbins \& Krueger, 2005). Apparently, people prefer to assume similarity only with others with whom they feel comfortable experiencing communion (such as liked, close, or ingroup others).

Although communion is typically circumscribed, some people draw more expansive circles of communion than others. People who place little value on communion may draw their boundary at 
the border of the self. They prefer to experience themselves as distinct and independent, even from close others. Indeed, they may be particularly guarded with people with whom they share a nominal bond because it is with them that they feel the most pressure to give, to receive, and to conform; however, to the extent that they do not experience relationships and group memberships as engendering strong bonds of mutual obligation, they may be less attentive than most people are to who is inside or outside those social categories. People who place more value on communion enlarge their boundaries to include others (e.g., friends, partners, group members), and within that circle they cherish sharing commonality and mutuality; however, they may be correspondingly more discriminating about whom to include within that circle of fellowship. That is, the more people experience relationships and group memberships as engendering bonds of mutual obligation, the more they will be concerned about defining, clarifying, and solidifying the boundary between those with whom they share a connection and those with whom they do not.

The preceding discussion suggests that we refine our core hypothesis as follows: People with stronger communal values will assume greater similarity with others with whom they are or would feel comfortable being interconnected (e.g., friends, partners, ingroup members). A weak version of this hypothesis is that communal values are irrelevant to-and therefore not predictive of assumed similarity with-people outside the boundary of that circle of connection (e.g., disliked and outgroup others). A strong version of this hypothesis is that people who care more about their relationships and memberships will carefully guard those boundaries, and therefore will be more prone to deny or reject overlaps between themselves and others with whom they are not interconnected. If so, then communal values may actually predict assumed dissimilarity toward people outside the circle of communion.

\section{Overview of the Studies}

We tested our hypotheses in a series of five studies. In Study 1, students indicated their own political preferences and estimated other students' political preferences. In Studies 2-5, students rated their personality and the personalities of various target others. In Study 2, the target was an actual or a desired romantic partner. In Studies 3 and 4, the targets were students from one's own university or from a foreign university. In Study 5 , the targets were specific liked and disliked others. Across all of the studies, we predicted that people with stronger communal values would assume greater similarity with others with whom they were or would feel comfortable being interconnected (i.e., liked others, romantic partners, and peers at their institution), but not with others with whom they were not interconnected (i.e., disliked others and students in a foreign country). The studies also tested whether the findings would be robust across different cultures and when controlling for variables such as self-esteem and the social desirability of the attributes.

Most studies of assumed similarity have examined overall selfother similarity (the similarity between raw self-ratings and ratings of others). However, overall similarity conflates similarity due to sharing common attributes (that most people share) and similarity due to sharing uncommon attributes (that few people share). More precisely, an individual's rating on an attribute can be decomposed into a normative and a distinctive component (Cronbach, 1955;
Furr, 2008). The normative component is the average rating for that attribute across all individuals. The distinctive component is the degree to which the individual's rating is above or below that average. Similarity due to describing both the self and others as normative is normative self-other similarity. Similarity due to describing the self and others in the same distinctive terms is distinctive self-other similarity. In the context of estimating the prevalence of attributes in a population, distinctive self-other similarity is sometimes called "truly false consensus" because it represents the degree of assumed similarity that is not corroborated by actual prevalence rates (Krueger \& Clement, 1994). Because normative similarity and distinctive similarity represent different routes by which communal values might influence overall similarity, we assess both overall self-other similarity and its normative and distinctive components.

A third route by which communal values may influence selfother similarity is that people who value communion may have relatively positive impressions of themselves and people connected to the self. Many researchers have noted that because people describe themselves favorably (Taylor \& Brown, 1988), if people also describe others favorably, then self-other similarity could be due to similarly favorable descriptions rather than similarity in the non-valuative content of the descriptions (Riketta \& Sacramento, 2008; Robbins \& Krueger, 2005; Sherman, Chassin, Presson, \& Agostinelli, 1984; Toma et al., 2010). Extending that logic, Locke and Christensen (2007) suggested (but did not formally test the hypothesis) that the tendency for people with strong communal values to describe themselves and their friends in favorable terms might be sufficient to explain why people with stronger communal values assume greater self-friend similarity. To test this possibility, we tested whether trait desirability mediates the effects of communal values on assumed trait similarity in Studies 2-5.

To summarize, our key hypothesis was that people with stronger communal values would assume greater similarity with targets with whom they were or felt comfortable being interconnected; however, we also assessed three ways that might occur. If differences in overall similarity are due to being similarly desirable, then it suggests people who value communion endorse attributes that convey "we're both equally worthy of esteem." If differences in overall similarity are due to being similarly normative, then it suggests people who value communion endorse attributes that convey "we're both normal and fit in." If differences in overall similarity are due to being similarly distinctive, then it suggests people who value communion endorse attributes that convey "we share a distinct identity."

\section{Study 1}

Our first investigation concerned the assumed similarity of political preferences-specifically, U.S. students' estimates of whether other students shared their preferences for president. Several previous studies have also assessed assumed consensus for political opinions (e.g., Granberg \& Brent, 1983; Koestner, Losier, Worren, Baker, \& Vallerand, 1995), but none evaluated the present hypothesis-namely, that people with stronger communal values would believe that more people share their preferences. 


\section{Method}

Participants. University of Idaho undergraduates (49 women, 30 men, one unknown; $M$ age $=19.5$ years, $S D=2.2$ ) participated for extra credit in psychology courses. The participants' self-reported ethnic backgrounds were 90.0\% European American, 2.5\% Hispanic, 2.5\% Asian American, 2.5\% Native American, and $2.5 \%$ unreported.

Circumplex Scales of Interpersonal Values (CSIV). The CSIV (Locke, 2000) is a self-report measure of agentic and communal values. The CSIV specifically consists of eight 8-item scales designed to assess each octant of the interpersonal circumplex defined by the orthogonal axes of agency and communion. For each item, respondents indicate how important it is that they act, appear, or are treated that way during social interactions on 0 (not important) to 4 (extremely important) scales. All items begin: "When I am with him/her/them, it is important that ..." Examples of high communion items are ". . . I feel connected to them" and "... they support me when I am having problems." Sample low-communion items are ". . I I keep my guard up" and "... they keep their distance from me." Sample high-agency and low-agency items are, respectively, “... I not back down when disagreements arise" and "... they not get angry with me." (The complete CSIV, norms, and scoring information are available at www.class.uidaho.edu/klocke/csiv.htm.) The CSIV has convergent and discriminant validity with measures of interpersonal traits, interpersonal problems, interpersonal self-efficacy, interpersonal sensitivities, interpersonal goals, implicit interpersonal motives, and various other personality and personality disorder measures (Hopwood et al., 2011; Kammrath \& Scholer, 2011; Locke, 2000; Locke \& Sadler, 2007).

To formally test whether the CSIV scales met the criteria for a circumplex model in the present sample, a randomization test of hypothesized order relations was conducted (Hubert \& Arabie, 1987; Tracey, 2000). Perfect fit to a circular model requires that correlations of adjacent scales on the circle exceed correlations of scales two octants apart, which in turn exceed those of scales three octants apart, which in turn exceed those of scales opposite on the circle. In total, a circular model makes 288 predictions about the relative magnitudes of correlations among eight octant scales. The program RANDALL (Tracey, 1997) computes the number of these predictions met in a particular sample and a correspondence index (CI; Hubert \& Arabie, 1987) equal to the proportion of predictions met minus the proportion violated. The CI can range from -1.0 (all predictions violated) to 1.0 (perfect fit). Running RANDALL on the mean-centered CSIV scales, 276 of the 288 predictions were met $(C I=.92, p<.001)$, indicating significant conformity to a circular model.

Because the CSIV octant scales formed a circumplex, the scales were summarized in terms of two underlying vectors using the following formulae (Leary, 1957, p. 69): Agentic Values = $\Sigma S_{\mathrm{i}} \sin \theta_{\mathrm{i}}$ and Communal Values $=\Sigma \mathrm{S}_{\mathrm{i}} \cos \theta_{\mathrm{i}}$, where $\mathrm{S}_{\mathrm{i}}$ is the ith octant score, $\theta_{i}$ is the angle at the center of that octant, and the angles of the "high communion" and "high agency" octants are, respectively, $0^{\circ}$ and $90^{\circ}$. Cronbach's alphas for the agentic values dimension and communal values dimension were 0.83 and $0.93{ }^{1}$

Procedure. Participants completed a questionnaire during one of four group testing sessions: the week before the 1996 U.S. presidential election $(n=18)$, election week $(n=18)$, 1 week after the election $(n=22)$, and 2 weeks after the 1996 election ( $n=22$ ). Participants (a) completed the CSIV; (b) indicated whether they most supported Bob Dole, Bill Clinton, or Ross Perot (the main presidential candidates); and (c) indicated "what percentage of University of Idaho students your age do you think support each of the presidential candidates."

\section{Results and Discussion}

The percentage of our respondents who supported Clinton, Dole, and Perot were, respectively, $52.5 \%, 25 \%$, and $22.5 \%$. The key outcome of interest was the percentage of other students who respondents believed shared their preference. The mean percentage of estimated agreement was $52.1 \%(S D=12.4)$ for Clinton supporters, $38.1 \%(S D=13.6)$ for Dole supporters, and $15.0 \%$ $(S D=7.9)$ for Perot supporters; thus, Perot supporters tended to underestimate and Dole supporters tended to overestimate other students' agreement.

The predictors of interest were interpersonal values. When we regressed estimated percentage of agreement on agentic and communal values, communal values predicted greater estimated agreement (standardized $\beta=.30, S E=.11, p=.01$ ), but agentic values $\operatorname{did} \operatorname{not}(\beta=.07, S E=.11)$. Analyses of variance showed that communal and agentic values were unrelated to respondents' candidate preferences, $F \mathrm{~s}(2,77) \leq 1.1, p \mathrm{~s}>.3$. However, because the candidates' actual popularity differed in our student sample, we computed "false consensus" by subtracting the actual percentages of support from respondents' estimates-that is, we subtracted $52.5 \%, 25 \%$, and $22.5 \%$ from the consensus estimates given by, respectively, Clinton, Dole, and Perot supporters. Regressing "false consensus" on interpersonal values again showed that communal values predicted greater false consensus $(\beta=.25, S E=.12$, $p<.05)$, but agentic values did not $(\beta=.08, S E=.12)$. (Which week data were collected and which candidate the respondent supported did not significantly influence or moderate the results.) In sum, the results supported the hypothesis that communal values predict assumed similarity.

\section{Study 2}

Study 1 assessed assumed similarity with other students in general. In Study 2, we assessed assumed similarity with a specific person — namely, a current or a desired romantic partner. It may be especially important for people who value communion to believe that they share attributes with close others; therefore, we expected communal values to be a strong predictor of assumed similarity with current romantic partners. In interpreting such findings, it should be noted, though, that individual differences in assumed similarity may reflect differences in actual similarity; that is, the partners of people who value communion may actually be more similar to them. Thus, desired future romantic partners provide an equally interesting target to study because assumed similarity with

\footnotetext{
${ }^{1}$ The reliabilities for the dimension scores were computed as $r_{\mathrm{yy}}=1-$ $\left(\left(\Sigma\left(1-\mathrm{r}_{\mathrm{ii}}\right) \mathrm{w}_{\mathrm{i}}^{2}\right) / \sigma_{\mathrm{y}}^{2}\right)$, where $\sigma_{\mathrm{y}}^{2}$ is the sample variance of the dimension scores (computed from $z$-scored octant scores), the $\mathrm{w}_{\mathrm{i}}$ are the weights (i.e., the $\sin$ or cos) of the octant scores, and $r_{i i}$ are the reliabilities of the octant scores.
} 
desired partners is a pure measure of preferences, independent of reality.

As noted in the introduction, one goal of Studies 2-5 was to test whether desirable responding mediates the effects of communal values. For example, in the present study, simply making relatively rosy ratings of both oneself and one's partner (without considering the traits' nonevaluative content) would enhance self-partner similarity. To test such a possibility, we had participants in Studies 2-5 rate themselves and others on carefully designed sets of desirable and undesirable traits, and then tested whether trait desirability mediated any moderating effects of communal values on assumed similarity. For simplicity, rather than reporting these analyses in each study separately, we wait and report them all in the results section of Study 5 .

\section{Method}

Participants. University of Idaho undergraduates (230 women, 147 men, four unknown; $M$ age $=20.7$ years, $S D=4.2$ ) participated for extra credit in psychology courses. ${ }^{2}$ The participants' self-reported ethnic background were $85.6 \%$ European American, 5.8\% Hispanic, 3.9\% "mixed" or "other," $3.4 \%$ African-, Asian-, or Native American, and 1.3\% no response.

\section{Materials.}

CSIV. Using the same data and selection procedures described in Locke (2000), four items from each CSIV scale were selected to create a 32-item short form. A randomization test of hypothesized order relations on the mean-centered CSIV scales showed 268 of the 288 predictions were met $(C I=.86, p<.001)$, indicating significant fit to a circular model. Because the octant scales conformed to a circumplex, they were combined into overall indices of agentic and communal values. Cronbach's alphas for the agentic values dimension and communal values dimension were, respectively, 0.60 and 0.81 .

Traits. Sixty traits that collectively covered all levels of social desirability but did not confound trait desirability with trait content were carefully selected. We began with a pool of traits for which there were social desirability norms from two independent samples (Hampson, Goldberg, \& John, 1987; Norman, 1967). In both samples, participants had rated the social desirability of each trait on a 1 (extremely undesirable) to 9 (extremely desirable) scale. The norms from the two samples were averaged to obtain a more stable index of desirability. Then traits that were contrasting in meaning but whose mean social desirability ratings were within .5 units of each other were paired together. Five such pairs at each of six levels of social desirability were selected. The pairs were as follows: ambitious-easy-going, practical-principled, livelyrelaxed, independent-sociable, adaptable-stable (desirability between 7 and 8); humble-bold, modest-daring, dignified-playful, firm-accommodating, frank-sensitive (desirability between 6 and 7); reserved-mischievous, soft-tough, outspoken-quiet, compliant-forceful, cautious-carefree (desirability between 5 and 6); docile-dominant, conventional-rebellious, shy-dramatic, bashful-flirtatious, restrained-rambunctious (desirability between 4 and 5); highly strung-lethargic, impatient-indecisive, immodest-inhibited, submissive-argumentative, meekdemanding (desirability between 3 and 4); self-pitying-conceited, irritable-apathetic, unsociable-nosey, distrustful-gullible, vaininsecure (mean desirability between 2 and 3 ).
Procedure. All participants completed the CSIV and then rated themselves on the 60 (randomly ordered) traits. Next, participants who were currently in a romantic relationship $(n=198)$ rated how well each trait described their romantic partner, and participants who were not in a relationship $(n=183)$ indicated how well each trait "describes the romantic partner with whom you would be most compatible." All trait ratings were made on scales ranging from -2 (strongly disagree) to 0 (neither) to +2 (strongly agree).

\section{Results}

Data analysis for Studies 2-5. In Studies 2-5, participants rated themselves and others on sets of personality traits. Because ratings are nested within participants, in keeping with current practice (e.g., Human \& Biesanz, 2011; Riketta \& Sacramento, 2008), we used multilevel random coefficient modeling to analyze the data. Multilevel modeling allowed us to estimate potential moderators of self-other similarity at both the trait level (e.g., desirability, target) and rater level (e.g., communal and agentic values).

The continuous variables were $z$-scored (using the sample mean and standard deviation). The binary variables were effect-coded (i.e., in Studies 3-4, outgroup or Asian $=-1$, ingroup or American $=+1$; in Study 5, disliked others $=-1$, liked others $=+1$ ); thus, effects of these binary variables will indicate half the standard deviation change expected due to the trait or person being in different categories. Unless otherwise specified, the significance level for all tests was .01, and we only report significant effects. In all analyses, we tested first linear effects, then two-way interactions (controlling for linear effects of the constituent variables), and finally three-way interactions (again controlling for lower order effects). Because there were no significant simple effects or interpretable interactions involving gender, we omitted gender from the analyses.

Overall similarity. To analyze overall self-partner similarity, the trait-level (Level 1) model was:

$$
\text { Partner }_{\mathrm{ik}}=\beta_{0 \mathrm{i}}+\beta_{1 \mathrm{i}} \text { Self }_{\mathrm{ik}}+\mathrm{e}_{\mathrm{ik}},
$$

where Partner ${ }_{\mathrm{ik}}$ and Self $_{\mathrm{ik}}$ are participant $i$ 's partner rating and self-rating on trait $k ; \beta_{0 i}$ is the predicted partner rating at the self-rating mean; $\beta_{1 \mathrm{i}}$ is participant $i$ 's overall similarity coefficient; and $\mathrm{e}_{\mathrm{ik}}$ is the residual.

The rater level (Level 2) model was:

$$
\begin{aligned}
& \beta_{0 \mathrm{i}}=\beta_{00}+\beta_{01}\left(\text { Communal }_{\mathrm{i}}\right)+\beta_{02}\left(\text { Agentic }_{\mathrm{i}}\right)+u_{0 \mathrm{i}} \\
& \beta_{1 \mathrm{i}}=\beta_{10}+\beta_{11}\left(\text { Communal }_{\mathrm{i}}\right)+\beta_{12}\left(\text { Agentic }_{\mathrm{i}}\right)+u_{1 \mathrm{i}},
\end{aligned}
$$

where Communal ${ }_{\mathrm{i}}$ and Agentic $_{\mathrm{i}}$ are participant $i$ 's CSIV scores for communal and agentic values, respectively; $\beta_{11}$ and $\beta_{12}$ (the fixed effects of primary interest) indicate whether interpersonal values predict variation in the Level 1 slopes (i.e., overall similarity); $u_{0}$ and $\mathrm{u}_{\mathrm{Oi}}$ are residuals.

\footnotetext{
${ }^{2}$ Because we did not follow up on Study 1 for 9 years, whereas Study 1 was conducted in 1996, Studies 2-5 were conducted between the fall of 2005 and the spring of 2011.
} 
We conducted the analyses separately on participants who were in a relationship (and so described their current partner) and participants who were not in a relationship (and so imagined a compatible partner). Self-ratings strongly predicted ratings of both real and imagined partners $(\beta \mathrm{s}=.385$ and $.544 ; S E \mathrm{~s}=.022$ and .016 , $p \mathrm{~s}<.001)$. Communal values predicted even greater similarity between the self and both real and imagined partner ( $\beta \mathrm{s}=$ .096 and $.075, S E s=.022$ and $.017, p s<.001)$. Figure 1 displays the estimated simple slopes for assumed self-other similarity across a wide range of communal values and shows that the increase in assumed similarity as a function of communal values was sizable.

Normative and distinctive similarity. The normativeness of a set of self-ratings refers to their similarity to a set of normative (average) self-ratings (Furr, 2008). Therefore, to analyze the normativeness of self-ratings, we first computed the normative selfrating for each trait. Then we used the model shown in Equations $1-3$, but changed the Level 1 model to:

$$
\text { Self }_{\mathrm{ik}}=\beta_{0 \mathrm{i}}+\beta_{1 \mathrm{i}} \text { Norm }_{\mathrm{k}}+\mathrm{e}_{\mathrm{ik}},
$$

where $\operatorname{Norm}_{\mathrm{k}}$ is the normative self-rating for trait $k$. Normative self-ratings were, of course, powerful predictors of individual participants' self-ratings $(\beta=.504, S E=.009, p<.001)$. More interesting, people with stronger communal values made more normative self-ratings $(\beta=.104, S E=.010, p<.001)$. Therefore, communal values may predict greater self-other similarity because communal values predict ascribing normative or typical qualities to both self and others. To address this possibility, below we distinguished normative from distinctive similarity.

We computed each participant's distinctive self-rating for each trait by subtracting the normative rating for that trait from the participant's self-rating. Next, we used the basic model shown in Equations 1-3, but replaced overall self-ratings with normative and distinctive self-ratings. ${ }^{3}$ Thus, the Level 1 model was:

$$
\text { Partner }_{\mathrm{ik}}=\beta_{0 \mathrm{i}}+\beta_{1 \mathrm{i}} \text { Normative }_{\mathrm{ik}}+\beta_{2 \mathrm{i}} \text { Distinctive }_{\mathrm{ik}}+\mathrm{e}_{\mathrm{ik}} \text {, }
$$

where Distinctive ${ }_{\mathrm{ik}}$ is participant $i$ 's distinctive self-rating on trait $k, \beta_{1 \mathrm{i}}$ shows partner $i$ 's normative similarity (i.e., similarity to the sample's normative self-ratings), and $\beta_{2 \mathrm{i}}$ shows partner $i$ 's distinctive similarity (i.e., similarity to participant $i$ 's distinctive selfratings). The Level 2 model was accordingly expanded to include:

$$
\beta_{2 \mathrm{i}}=\beta_{20}+\beta_{21}\left(\text { Communal }_{\mathrm{i}}\right)+\beta_{22}\left(\text { Agentic }_{\mathrm{i}}\right)+\mathrm{u}_{2 \mathrm{i}} .
$$

Normative self-ratings strongly predicted partner ratings ( $\beta$ s for real and imagined partners $=.470$ and $.615, S E s=.017$ and .012 , $p$ s $<.001)$. Distinctive self-ratings also predicted partner ratings ( $\beta$ s for real and imagined partners $=.143$ and $.260, S E s=.018$ and $.014, p s<.001)$. Examining the coefficients shows that normative similarity exceeded distinctive similarity, and similarity to imagined partners exceeded similarity to real partners. As hypothesized, communal values moderated similarity. Greater communal values predicted greater normative similarity ( $\beta$ s for real and imagined partners $=.089$ and $.050, S E \mathrm{~s}=.016$ and $.012, p s<.001)$ and marginally greater distinctive similarity ( $\beta$ s for real and imagined partners $=.038$ and $.033, S E \mathrm{~s}=$ .018 and $.014, \mathrm{ps}<.05)$.

\section{Discussion}

The fact that people described their current or desired partner as similar to themselves accords with previous research (Botwin, Buss, \& Shackelford, 1997). Of greater interest was that communal values magnified the tendency to assume partners were similar. One caveat is that people with stronger communal values may report greater similarity with their partners because their partners in reality are more similar; however, the greater similarity between the self and imagined partners suggests that communal values influence desired (and not just actual) levels of similarity.

\section{Study 3}

In this study, we asked American participants to describe the self, other students from their university, and students from a university in Korea. Likewise, we asked Korean participants to describe the self, other students from their university, and students from a university in the United States. Study 3 extended our investigation in several ways. First, in Studies 1-2, we tested only whether or not communal values predicted assumed similarity for liked or ingroup targets; in Study 3 (along with Studies 4-5), we tested whether or not communal values predicts assumed similarity for outgroup targets (such as students at a foreign university). Second, studying both Americans (who completed the study in English) and Koreans (who completed the study in Korean) allowed us to test the generalizability of the findings across cultures and languages. Third, greater self-esteem predicts greater assumed self-other similarity (Human \& Biesanz, 2011) and is also associated with stronger communal values (Locke \& Christensen, 2007); therefore, self-esteem could explain the association between communal values and assumed similarity. In Study 3, we assessed whether the effects of communal values would remain robust, even controlling for self-esteem.

\section{Method}

Participants. The participants were American undergraduates (152 women, 61 men, four unknown; $M$ age $=20.1$ years, $S D=3.2)$ from the University of Idaho and South Korean undergraduates ( 110 women, 113 men; $M$ age $=23.4, S D=3.0$ ) from Baejae $(n=32)$, Dongkuk $(n=130)$, and Hansung $(n=62)$ Universities. The American participants' self-reported ethnic background was $83.9 \%$ European American, 6.0\% Hispanic, 4.6\% mixed/"other," $1.8 \%$ African American, 1.8\% Native American, and $1.8 \%$ no response. Korean students were not asked their ethnicity. American students received extra credit and Dongkuk University students received school cafeteria coupons for participating. Baejae and Hansung University students received no compensation.

Materials.

Traits. Forty-four (22 desirable and 22 undesirable) traits were used. Of these, 24 were from the set developed by Haslam and Bain (2007). Haslam and Bain categorized traits into eight

\footnotetext{
${ }^{3}$ An example of this procedure being used to model normative and distinctive components of self-other similarity can be found in Human and Biesanz (2011), and a detailed rationale for the procedure can be found in Biesanz (2010).
} 


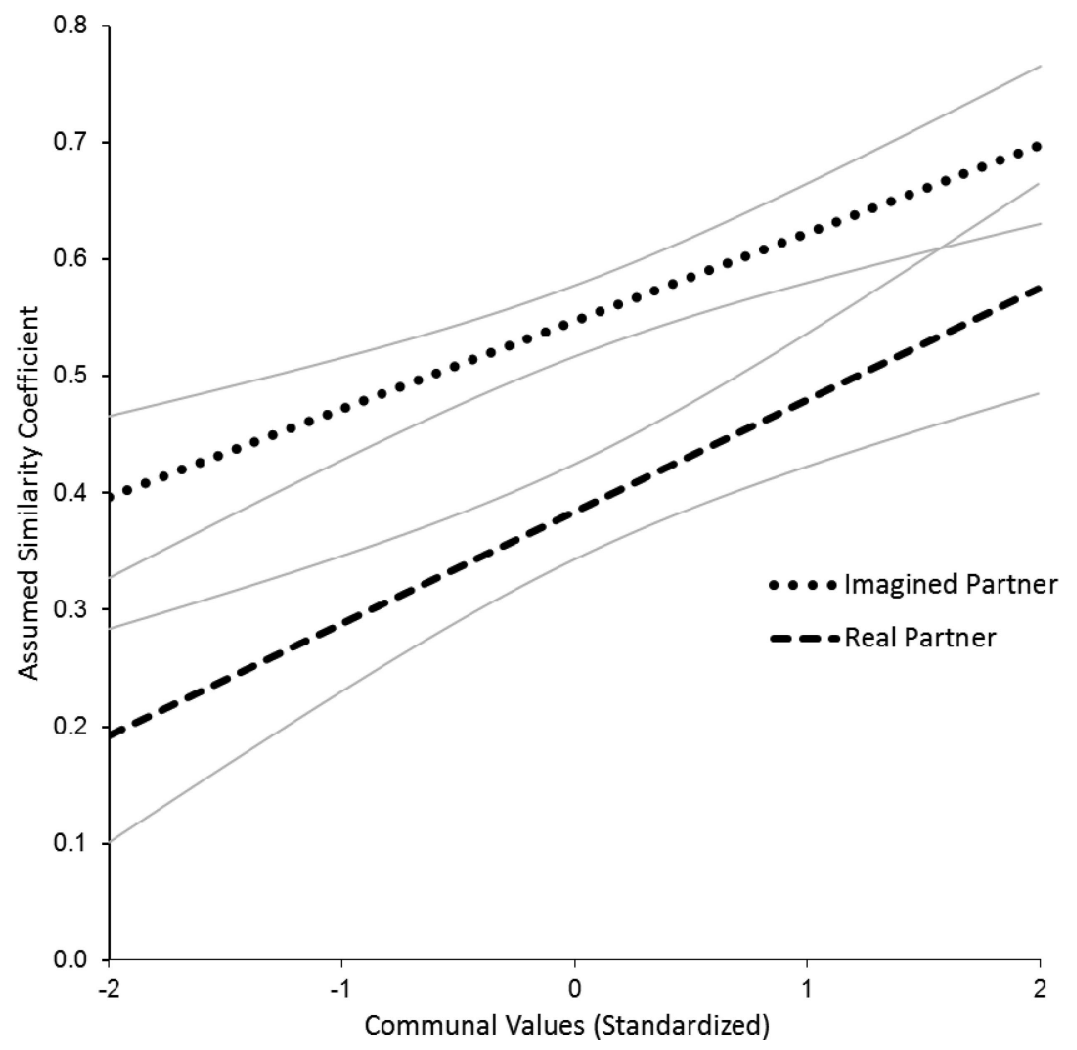

Figure 1. Assumed similarity coefficients as a function of communal values in Study 2. At each level of communal values, the pale curved lines show the 95\% confidence bands (continuously plotted confidence intervals) around the estimated simple slopes for assumed similarity. We computed the equations for the confidence bands using the formulas provided by Bauer and Curran (2005) and online utilities provided by Preacher, Curran, and Bauer (2006).

categories based on whether they were high or low with respect to three dimensions: desirability, being uniquely human, and reflecting human nature. Three traits from each of their eight categories were used. The other 20 traits consisted of five sets of "trait quartets" similar to those developed by Hampson (1998). As Table 1 shows, within each trait set all of the traits loaded on one factor of the five-factor model of personality, but two of the traits were desirable (with one from each pole of the factor) and two were undesirable (again with one from each pole of the factor). Using these 44 traits ensured that trait desirability was not confounded with either the five-factor model dimensions or Haslam and Bain's "humanizing-dehumanizing" dimensions.

Interpersonal values. Using the same data and selection procedures described in Locke (2000), two items from each CSIV scale were selected to create a 16 -item short form of the CSIV. A randomization test of hypothesized order relations on the meancentered CSIV scales showed 264 of the 288 predictions were met in the Korean sample and 271 of the 288 predictions were met in the American sample $(C I \mathrm{~s}=.86, \mathrm{ps}<.001)$, indicating significant fit to a circular model in both countries. Cronbach's alphas for the agentic values dimension and communal values dimension were 0.48 and 0.56 in America and .55 and .62 in Korea.

Self-esteem. The Rosenberg Self-Esteem Scale (Rosenberg, 1965) was used, a popular 10-item self-report measure of overall self-esteem; for its psychometric properties, see Gray-Little, Williams, and Hancock (1997). Cronbach's alphas in America and Korea were .89 and .86. As expected, self-esteem correlated positively with communal and agentic values, $r s(339)=.29$ and .27 , $p$ s $<.001$

Procedure. The materials were translated from English into Korean, and then back-translated to ensure accuracy. The study was administered online. First, participants completed the CSIV. Then, participants described three targets. Korean students described themselves, most students at their university (their ingroup), and most students at the University of Idaho (their outgroup). American students described themselves, most students at their university (their ingroup), and most students at Hansung University (their outgroup). Korean students were told that the University of Idaho was an American university similar in size and structure to their university, and American students received the analogous information about Hansung University. The participants rated how well each of the 44 traits described each target on scales ranging from -2 (very untrue) to 0 (neither) to +2 (very true). (Participants were randomly assigned to rate the targets in one of these two orders: ingroup-self-outgroup or outgroup-self-ingroup. Order had no effect on the results and so will not be discussed further.) 
Table 1

Evaluatively and Descriptively Contrasting Trait Quartets Used in Studies 3-5

\begin{tabular}{|c|c|c|c|c|}
\hline \multirow[b]{2}{*}{ Personality dimension } & \multicolumn{2}{|c|}{ High on dimension } & \multicolumn{2}{|c|}{ Low on dimension } \\
\hline & Desirable & Undesirable & Desirable & Undesirable \\
\hline \multicolumn{5}{|l|}{ Agreeableness } \\
\hline Study 3 & cooperative & intrusive & independent & unsociable \\
\hline Study 4 & trusting & gullible & not easily fooled & cynical \\
\hline Study 5 & tactful & vague & straightforward & abrupt \\
\hline \multicolumn{5}{|l|}{ Conscientiousness } \\
\hline Study 3 & organized & fussy & carefree & sloppy \\
\hline Study 4 & careful & fussy & carefree & sloppy \\
\hline Study 5 & self-disciplined & rigid & uninhibited & unstable \\
\hline \multicolumn{5}{|l|}{ Extraversion } \\
\hline Study 3 & decisive & domineering & accommodating & timid \\
\hline Study 4 & self-confident & arrogant & humble & self-doubting \\
\hline Study 5 & outspoken & boastful & modest & withdrawn \\
\hline \multicolumn{5}{|l|}{ Neuroticism } \\
\hline Study 3 & sensitive & irritable & levelheaded & bored \\
\hline Study 4 & sensitive & irritable & levelheaded & unemotional \\
\hline Study 5 & spirited & temperamental & stable & unemotional \\
\hline \multicolumn{5}{|l|}{ Openness to Experience } \\
\hline Study 3 & cultured & unrealistic & practical & uncultured \\
\hline Study 4 & imaginative & unrealistic & realistic & unimaginative \\
\hline Study 5 & cultured & snobbish & down-to-earth & coarse \\
\hline
\end{tabular}

\section{Results}

Overall similarity. To analyze overall assumed similarity, the Level 1 model was:

$$
\begin{aligned}
\text { Other }_{\mathrm{ijk}}= & \beta_{0 \mathrm{ij}}+\beta_{1 \mathrm{ij}} \text { Self }_{\mathrm{ik}}+\beta_{2 \mathrm{ij}} \text { Target }_{\mathrm{j}}+\beta_{3 \mathrm{ij}}\left(\text { Self }_{\mathrm{ik}} \times \text { Target }_{\mathrm{j}}\right) \\
& +\mathrm{e}_{\mathrm{ijk}},
\end{aligned}
$$

where Other $_{\mathrm{ijk}}$ and Self $_{\mathrm{ik}}$ are participant $i$ 's other rating and selfrating on trait $k$; Target ${ }_{j}$ is the effect code indicating whether the rating was of the ingroup or outgroup; and $\beta_{1 \mathrm{ij}}, \beta_{2 \mathrm{ij}}$, and $\beta_{3 \mathrm{ij}}$ are the mean effects of self-rating, target, and their interaction for target $i$. At Level 2, the Level $1 \beta$ s were regressed on country, communal and agentic values, self-esteem, and the Values $\times$ Country and Esteem $\times$ Country interactions. For example, the overall effect of self-ratings on other ratings was modeled as:

$$
\begin{aligned}
& \beta_{1 \mathrm{ij}}=\beta_{10}+\beta_{11}\left(\text { Communal }_{\mathrm{i}}\right)+\beta_{12}\left(\text { Agentic }_{\mathrm{i}}\right)+\beta_{13}\left(\text { Esteem }_{\mathrm{i}}\right) \\
& +\beta_{14}\left(\text { Country }_{\mathrm{i}}\right)+\beta_{15}\left(\text { Country } \times \text { Communal }_{\mathrm{i}}\right) \\
& +\beta_{16}\left(\text { Country } \times \text { Agentic }_{\mathrm{i}}\right)+\beta_{16}\left(\text { Country } \times \text { Esteem }_{\mathrm{i}}\right) \\
& +\mathrm{u}_{1 \mathrm{ij}}
\end{aligned}
$$

where Country ${ }_{\mathrm{i}}$ is the effect code indicating whether the participant was Korean or American; $\beta_{10}$ is the mean overall assumed similarity; and the other $\beta s$ (the fixed effects of primary interest) indicate whether the person-level variables predict variation in assumed similarity.

Self-ratings strongly predicted other ratings $(\beta=.317, S E=$ $.013, p<.001)$. Similarity was influenced by country $(\beta=.035$, $S E=.013)$ and the Country $\times$ Target interaction $(\beta=-.052$, $S E=.010, p s<.01)$. Simple effects analyses showed that in addition to similarity being greater in America than Korea, in Korea self-ingroup similarity exceeded self-outgroup similarity $(\beta \mathrm{s}=.330$ and .224, SEs $=.023$ and .024$)$, whereas in America self-outgroup similarity exceeded self-ingroup similarity $(\beta \mathrm{s}=$ .413 and $.300, S E s=.025$ and .024$)$.

Self-other similarity was positively associated with greater selfesteem $(\beta=.043, S E=.013)$, greater communal values $(\beta=.055$, $S E=.014)$, and the Communal Values $\times$ Target interaction $(\beta=$ $.027, S E=.010, p s<.01)$. Simple effects analyses showed that communal values moderated self-ingroup but not self-outgroup similarity $(\beta \mathrm{s}=.083$ vs. .027, SEs $=.017)$. Figure 2 displays the simple slopes for assumed similarity across a range of communal values and shows that as communal values increased, there was a significant increase in self-ingroup (but not self-outgroup) similarity.

Normative and distinctive similarity. We computed the normative self-rating for each trait (separately in each country). Then, to examine the normativeness of self-ratings, we used the procedure described in Study 2. Normative self-ratings were, of course, powerful predictors of individuals' self-ratings $(\beta=.559, S E=.014, p<$ $.001)$. Agentic values predicted less normative self-ratings $(\beta=$ $-.041, S E=.013, p<.01)$, but because no other study found this effect, we do not discuss it further. In addition, the normativeness of self-ratings was positively associated with being Korean (vs. American) and with communal values and self-esteem ( $\beta \mathrm{s}=-.065, .084$ and .137, respectively; $S E$ s $=.014$ ). Such individual differences in normativeness may explain individual differences in overall selfother similarity; therefore, we tested the independent effects of the normative and distinctive components of self-ratings on other ratings.

To do so, we used the procedure described in Study 2, but in order to distinguish ingroup and outgroup targets, we used the following more complicated Level 1 equation:

$$
\begin{aligned}
\text { Other }_{\mathrm{ijk}}= & \beta_{0 \mathrm{ij}}+\beta_{1 \mathrm{ij}} \text { Normative }_{\mathrm{ik}}+\beta_{2 \mathrm{ij}} \text { Distinctive }_{\mathrm{ik}}+\beta_{3 \mathrm{ij}} \text { Target }_{\mathrm{j}} \\
& +\beta_{4 \mathrm{ij}}\left(\text { Normative }_{\mathrm{ik}} \times \text { Target }_{\mathrm{j}}\right)+\beta_{5 \mathrm{ij}}\left(\text { Distinctive }_{\mathrm{ik}}\right. \\
& \left.\times \text { Target }_{\mathrm{j}}\right)+\mathrm{e}_{\mathrm{ijk}} .
\end{aligned}
$$




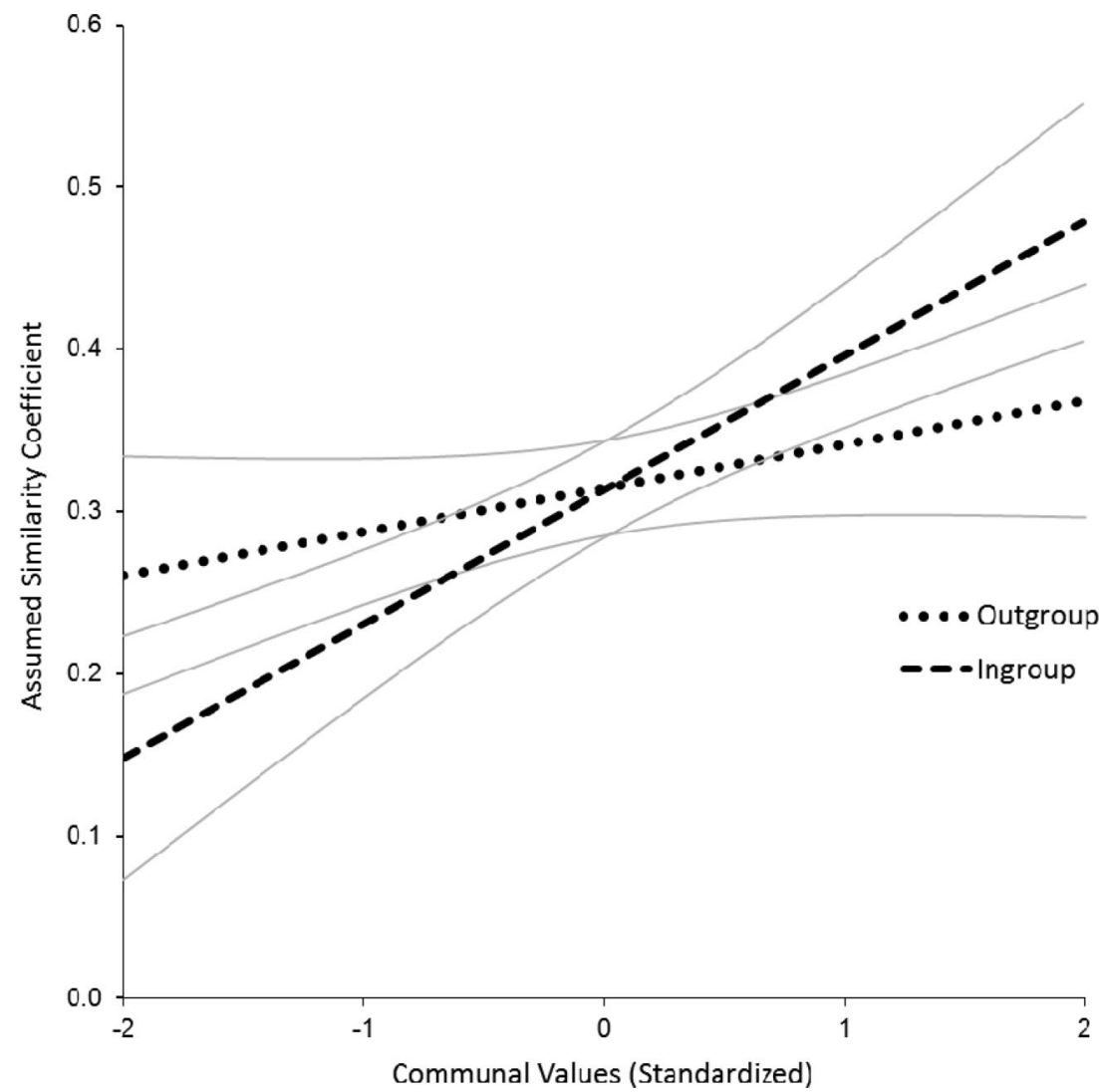

Figure 2. Assumed similarity coefficients as a function of communal values in Study 3. At each level of communal values, the pale curved lines show the $95 \%$ confidence interval around the estimated simple slopes for assumed similarity.

Both normative and distinctive self-ratings strongly predicted other ratings $(\beta \mathrm{s}=.353$ and .116, SEs $=.013$ and $.008, p \mathrm{~s}<$ $.001)$. Target and the Target $\times$ Country interaction moderated the effects of normative self-ratings $(\beta \mathrm{s}=-.037$ and $-.053, S E \mathrm{~s}=$ $.010)$ and distinctive self-ratings $(\beta s=.032$ and $-.020, S E \mathrm{~s}=$ $.008, p s \leq .01)$; specifically, distinctive self-ratings predicted ingroup ratings better than outgroup ratings in Korea $(\beta=.043$, $S E=.011)$ but not in America $(\beta=.004, S E=.011)$, whereas normative self-ratings predicted outgroup ratings better than ingroup ratings in America $(\beta=-.085, S E=.014)$ but not in Korea $(\beta=.025, S E=.017)$. Greater self-esteem predicted greater distinctive similarity $(\beta=.036, S E=.009, p<.001)$. Stronger communal values predicted greater normative similarity $(\beta=$ $.072, S E=.015, p<.001)$. Finally, the Communal Values $\times$ Target interaction predicted distinctive similarity $(\beta=.021, S E=$ $.008, p=.01)$; specifically, communal values predicted greater distinctive similarity with the ingroup $(\beta=.029, S E=.012)$ but not the outgroup $(\beta=-.008, S E=.009)$. Country did not moderate the effects of communal values on normative or distinctive similarity.

\section{Discussion}

Study 3 produced sundry interesting findings; here, we summarize just those that contribute to our understanding of the effects of communal values on assumed similarity. First, in accord with our previous studies, communal values predicted assumed similarity; moreover, the effect of communal values was similar in America and Korea. Second, in accord with our hypothesis that communion has bounds, communal values predicted distinctive similarity with ingroup members but not with outgroup members. Third, in accord with previous research (Human \& Biesanz, 2011), greater selfesteem predicted greater self-other similarity (especially distinctive similarity); however, controlling for self-esteem did not undermine the effects of communal values on self-other similarity.

\section{Study 4}

Study 4 replicated the basic procedure of Study 3 with two modifications. First, in order to further test the generalizability of the results, in Study 4 we compared participants from America and India. Second, previous research suggests that identifying with one's group has effects that parallel those we have observed for communal values. Riketta (2005) found that people who more strongly identify with their ingroup assume greater similarity with their ingroup and greater contrast with competing outgroups. Coats, Smith, Claypool, and Banner (2000) likewise found that group identification predicted the degree of implicit overlap between trait representations of the self and the ingroup. Therefore, in Study 4 we tested whether identifying with one's country (or 
national identification) would enhance assumed similarity with people from one's own country but not people from other countries and whether controlling for national identification would eliminate the effect of communal values.

\section{Method}

Participants. The participants were U.S. citizens attending the University of Idaho (147 women, 57 men, 19 unknown; $M$ age $=20.7$ years, $S D=4.2)$ and Indian citizens attending Gujarat University (120 women, 82 men; $M$ age $=20.1, S D=1.3$ ). The American participants' self-reported ethnic backgrounds were 81.2\% European American, 7.2\% "mixed," 4.9\% Hispanic, 6.3\% African-, Asian-, or Native-American or "other"; and $0.4 \%$ no response. Indian students reported their religion instead of their ethnicity; $78.2 \%$ were Hindu, $11.4 \%$ Jain, $7.9 \%$ Muslim, and $2.5 \%$ "other." American students received extra credit; Indian students received money.

Interpersonal values. The 64-item CSIV was administered. A randomization test of hypothesized order relations on the meancentered CSIV scales showed 238 of 288 predictions were met and one was tied $(C I=.66, p<.001)$ in the Indian sample and 286 of 288 predictions were met $(C I=.99, p<.001)$ in the American sample, indicating significant fit to a circular model in both countries (although the fit was better in the United States than in India). Cronbach's alphas for Agentic Values and Communal Values were 0.80 and 0.87 in America and .39 and .77 in India. Thus, the reliabilities were good, with the exception of agentic values in India.

Procedure. The materials were translated from English into Gujarati, and then back-translated to ensure accuracy. Indian students had the option of completing the questionnaire in English or in Gujarati; 74\% chose English. Participants completed the questionnaire during group testing sessions. First, participants indicated their national identification by rating "Being American [Indian] is an important part of my identity" on the following scale: -3 (disagree strongly), -2 (disagree somewhat), -1 (disagree slightly), +1 (agree slightly), +2 (agree somewhat), +3 (agree strongly). Second, participants completed the CSIV. Interestingly, national identification correlated with communal and agentic values in India only weakly, $r \mathrm{~s}(200)=.23$ and .16 , and in America not at all, $r \mathrm{~s}(221)=.03$ and .00 . Third, participants indicated how typical each of 20 traits was of (a) "you," (b) "most university students in India (who grew up in India)," and (c) "most university students in the United States (who grew up in America)." The ratings were made on three separate pages, and were made on the following scale: -3 (extremely atypical), -2 (very atypical), -1 (somewhat atypical), +1 (somewhat typical), +2 (very typical), +3 (extremely atypical). The traits (shown in Table 1) consisted of five trait quartets similar to those used in Study 3.

\section{Results}

Overall similarity. We used the same analytic model as in Study 3, except we replaced self-esteem with national identification. The effects of interest involved assumed similarity and the moderators of assumed similarity. Self-ratings strongly predicted other ratings $(\beta=.288, S E=.012, p<.001)$. Self-other similarity was moderated by target $(\beta=-.041, S E=.014)$ and the
Country $\times$ Target interaction $(\beta=-.179, S E=.013, p s<.01)$. Simple effects analyses showed that in India, self-ingroup similarity exceeded self-outgroup similarity $(\beta \mathrm{s}=.468$ and .185 , $S E \mathrm{~s}=.023$ and .035$)$, whereas in America, self-outgroup similarity exceeded self-ingroup similarity $(\beta \mathrm{s}=.407$ and $.057, S E \mathrm{~s}=$ .044 and .026). Stronger national identification predicted greater similarity $(\beta=.040, S E=.013, p<.01)$. Similarity was also moderated by the Target $\times$ Communal Values and Target $\times$ Agentic Values interactions $(\beta \mathrm{s}=.056$ and $-.046, S E \mathrm{~s}=.018$, $p \mathrm{~s} \leq .01)$. Simple effect analyses showed that communal values predicted greater ingroup but not outgroup similarity $(\beta \mathrm{s}=.092$ and $-.017, S E s=.028$ and .026), whereas agentic values predicted greater outgroup but not ingroup similarity $(\beta \mathrm{s}=.057$ and $-.032, S E \mathrm{~s}=.026$ and .027 ). Figure 3 displays the simple slopes for assumed similarity across a range of communal values and shows that as communal values increased, there was a significant increase in self-ingroup (but not self-outgroup) similarity.

Normative and distinctive similarity. The following analyses paralleled those used in Study 3. Normative self-ratings were powerful predictors of individuals' self-ratings $(\beta=.567, S E=$ $.013, p<.001)$. More interesting, stronger communal values predicted more normative self-ratings $(\beta=.098, S E=.022, p<$ $.001)$; thus, if people with stronger communal values describe themselves and others in similar terms, then it may be because they describe themselves and others in more normative terms. Therefore, we tested the independent effects of the normative and distinctive components of self-ratings on other ratings.

Both normative and distinctive self-ratings strongly predicted other ratings $(\beta \mathrm{s}=.304$ and .129, SEs $=.011$ and $.010, p \mathrm{~s}<$ $.001)$. Country, target, and the Target $\times$ Country interaction moderated distinctive self-other similarity $(\beta \mathrm{s}=-.039, .030$, and $-.057 ;$ SEs $=.012, .010$, and $.011, p \mathrm{~s}<.01)$; specifically, distinctive self-ingroup exceeded distinctive self-outgroup similarity in India but not in America $(\beta \mathrm{s}=.058 \mathrm{vs} .-.027$, SEs $=$ .019 and .015$)$. Target and the Target $\times$ Country interaction also moderated normative self-ratings $(\beta \mathrm{s}=-.101$ and $-.231, \mathrm{SEs}=$ .016 and $.012, p s<.001)$; specifically, normative self-ratings were in India more strongly associated with ingroup than outgroup ratings $(\beta=.108, S E=.027)$, but in the United States were more strongly associated with outgroup than ingroup ratings $(\beta=$ $-.307, S E=.017)$.

There were also effects of communal values and national identification. Normative similarity was positively associated with national identity and the National Identity $\times$ Target interaction $(\beta \mathrm{s}=.032$ and $.038, S E \mathrm{~s}=.012, p \mathrm{~s}<.01)$. Normative similarity showed similar but weaker associations with communal values and the Communal Values $\times$ Target interaction $(\beta \mathrm{s}=.045$ and .034 , $S E \mathrm{~s}=.018, p \mathrm{~s} \leq .06)$. Finally, the Communal Values $\times$ Target interaction predicted distinctive similarity $(\beta=.058, S E=.015$, $p<.001)$.

Analyzing ingroup and outgroup ratings separately clarified the reasons for the interactions. Stronger communal values and national identity predicted greater normative similarity with ingroup members $(\beta \mathrm{s}=.081$ and $.082, S E \mathrm{~s}=.028$ and $.025, \mathrm{ps}<.01)$, but not with outgroup members $(\beta \mathrm{s}=.020$ and $.000, S E \mathrm{~s}=.025$ and .021). Stronger communal values predicted marginally greater distinctive similarity with ingroup members $(\beta=.053, S E=.023$, $p=.02)$, but undermined distinctive similarity with outgroup members $(\beta=-.065, S E=.024, p<.01)$. 


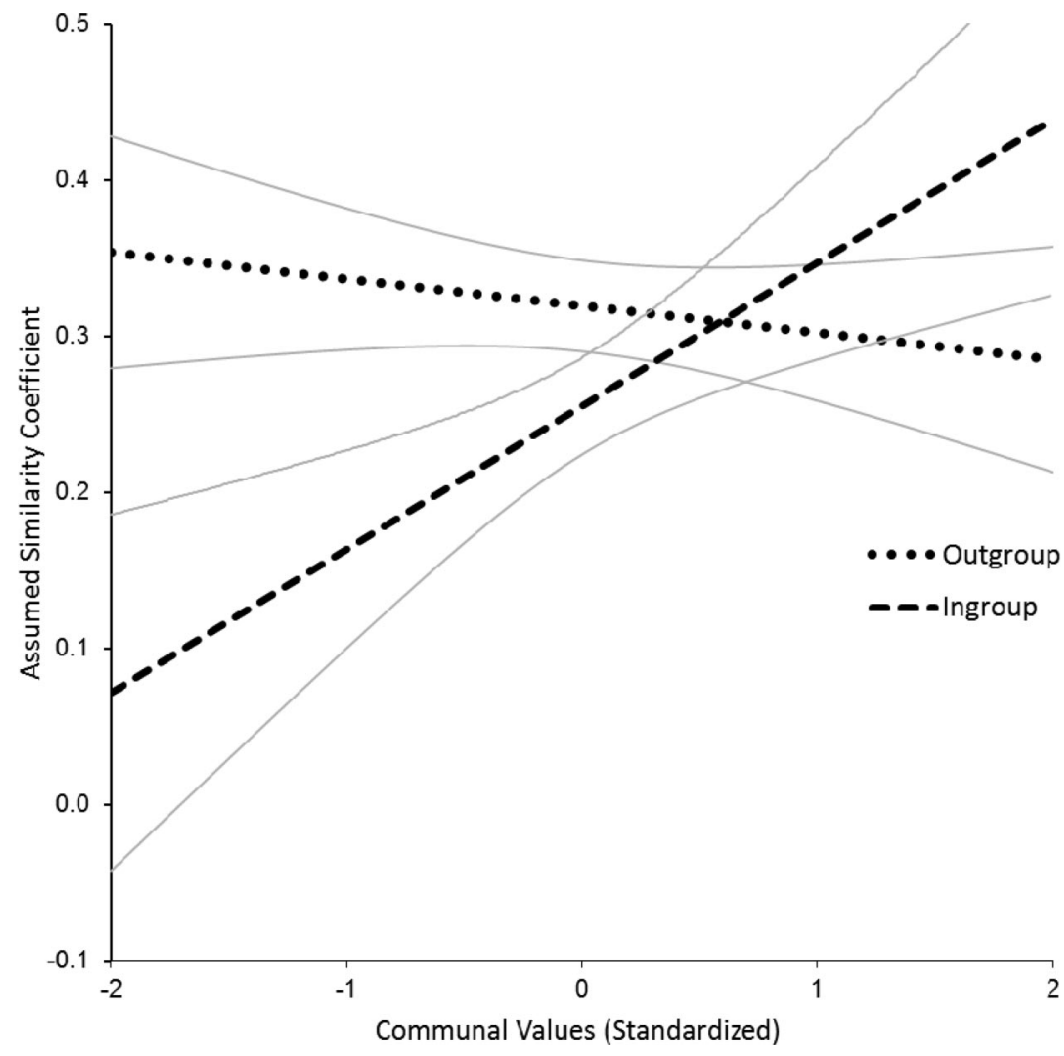

Figure 3. Assumed similarity coefficients as a function of communal values in Study 4. At each level of communal values, the pale curved lines show the $95 \%$ confidence interval around the estimated simple slopes for assumed similarity.

\section{Discussion}

Several results of Study 4 contribute to our understanding of the effects of communal values on assumed similarity. First, as in Study 3, communal values predicted assumed similarity with ingroup but not with outgroup members; indeed, people with stronger communal values were less likely to believe students from another country shared their distinctive traits. Second, the effect of communal values was similar in America and India. Third, in accord with previous findings suggesting that identifying with a group facilitates assumed similarity with that group but not competing groups (Riketta, 2005), identifying with one's country predicted greater normative similarity with students from one's own country but not students from a foreign country. Although the effects of national identification roughly paralleled those of communal values, national identification and communal values were only weakly correlated, and the effects of communal values remained robust even when controlling for identification.

\section{Study 5}

In the preceding studies, we examined assumed similarity with either romantic partners or groups of students. Study 5 complemented these studies by comparing the effects of communal values on assumed similarity with specific liked or disliked others. On the basis of decades of previous research (see Montoya et al., 2008), we expected similarity with liked others to exceed similarity with disliked others. More importantly, based on our hypothesis that communal values inspire both similarity and selectivity, we expected people with stronger communal values would show greater assumed similarity with liked but not disliked others.

\section{Method}

Participants. University of Idaho undergraduates (230 women, 152 men; age range $=18-43$ years, $M=20.5, S D=3.1$ ) participated for extra credit in psychology courses. Of those who reported their ethnicity, 86\% were European American; 6\% were mixed; $4 \%$ were Hispanic/Latino; and $4 \%$ were African American, Asian American, or Native American.

CSIV. The 32-item version of the CSIV used in Study 2 was used here. A randomization test of hypothesized order relations on the mean-centered CSIV scales showed 268 of the 288 predictions were met $(C I=.86, p<.001)$, indicating significant conformity to a circular model. Cronbach's alphas for the agentic values dimension and communal values dimension were, respectively, 0.67 and 0.85 .

Procedure. The participants completed the study at computer terminals in private booths. The participants made personality ratings of five different (randomly ordered) targets: two different individuals "whose friendship you enjoy and really value," two different individuals "towards whom you have very negative or at least mixed feelings," and their own personality "in general." Participants rated each target on 20 traits using 6-point scales 
ranging from -3 (strongly disagree) to +3 (strongly agree); there was no " 0 " or "neutral" option. The traits are shown in Table 1 and consisted of five trait quartets similar to those used in Studies 3-4. The participants then completed the CSIV.

Finally, the participants rated each trait on scales ranging from -3 (very undesirable) to +3 (very desirable) with respect to "how desirable do you think it is" and "how desirable most people think it is." These ratings were obtained for the purpose of testing whether trait desirability mediates the effects of communal values. Participants' ratings of "how desirable do you think it is" powerfully predicted their ratings of "how desirable most people think it is" (standardized $\beta=.827, S E=.012, p<.001$ ). Interestingly, the association was stronger for people with stronger communal values $(\beta=.030, S E=.012, p=.01)$; they were more likely to assume others shared their evaluations of trait desirability. Given the strong association between participants' two ratings of each trait, the ratings were averaged to yield a more stable measure of perceived trait desirability.

\section{Results}

The analyses mirrored those used in Studies 3-4 except that in Study 5, Target referred to liked versus disliked (rather than ingroup versus outgroup) targets.

Overall similarity. Self-ratings strongly predicted other ratings $(\beta=.225, S E=.011, p<.001)$. Liking moderated this association $(\beta=.349, S E=.010)$; specifically, self-ratings were associated positively with ratings of liked others $(\beta=.576, S E=$ $.014)$ and negatively with ratings of disliked others $(\beta=-.130$, $S E=.016, p<.001 ; p \mathrm{~s}<.001)$. The self-other association was also moderated by communal values $(\beta=.046, S E=.011)$ and the Communal Values $\times$ Liking interaction $(\beta=.034, S E=.010$, $p$ s $\leq .001)$; specifically, greater communal values predicted greater similarity between the self and liked others $(\beta=.080$, $S E=.014, p<.001)$ but not between the self and disliked others $(\beta=.013, S E=.016)$. Figure 4 displays the simple slopes for assumed similarity across a range of communal values and shows that people assumed greater similarity with liked than with disliked others and that this was especially true for people with stronger communal values.

Normative and distinctive similarity. Normative selfratings were powerful predictors of individuals' self-ratings $(\beta=$ $.668, S E=.012, p<.001)$, and the normativeness of self-ratings was greater for people with stronger communal and (to a lesser extent) agentic values ( $\beta \mathrm{s}=.129$ and $.043, S E \mathrm{~s}=.013$ and .012 , $p s<.001$ ). (Because no other study found this positive effect of agentic values, we do not discuss it further.) Next, to test whether the normativeness of self-ratings explains why communal values predict greater self-other similarity, we modeled the independent effects of the normative and distinctive components of self-ratings on other ratings.

Both normative and distinctive self-ratings strongly predicted other ratings $(\beta \mathrm{s}=.221$ and $.101, S E \mathrm{~s}=.010, p \mathrm{~s}<.001)$. Liking

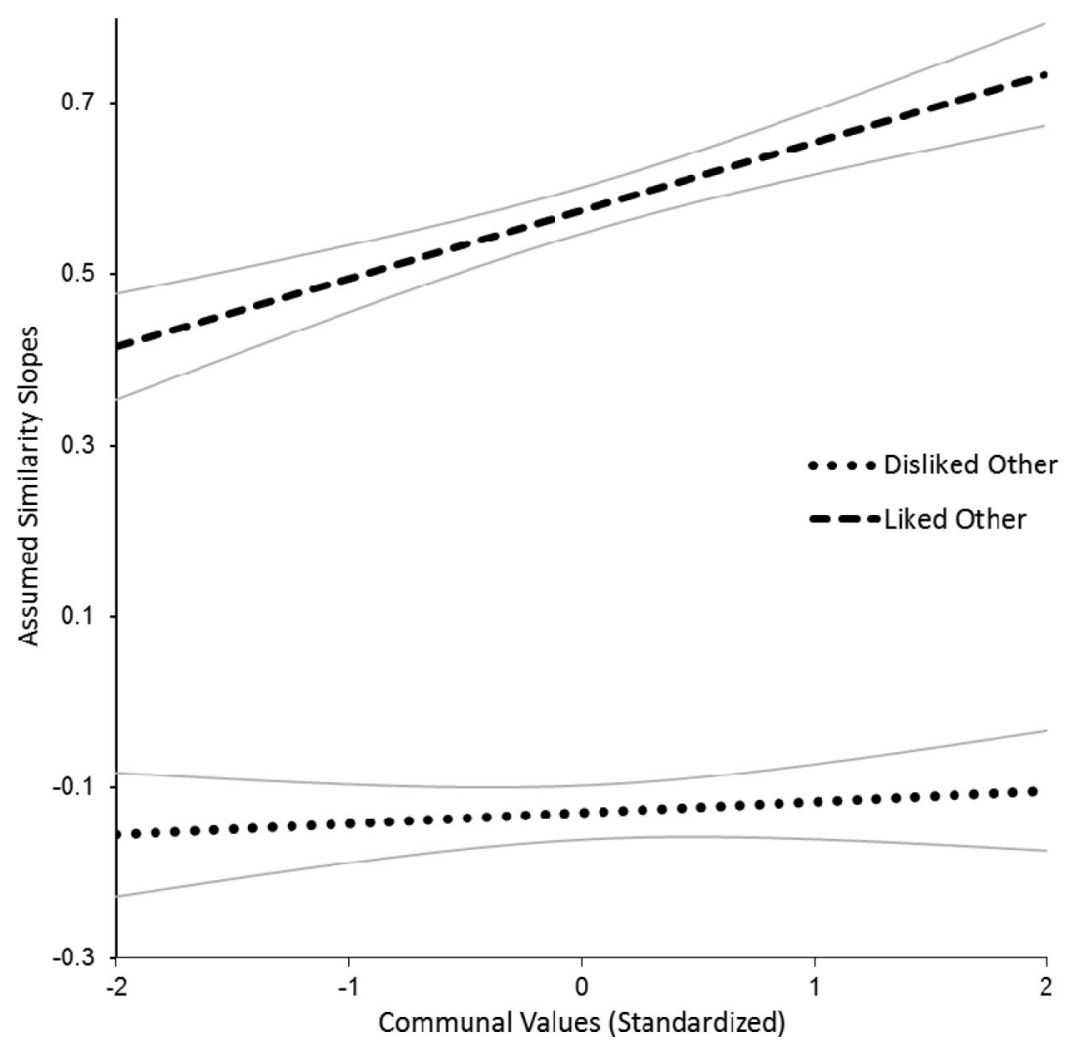

Figure 4. Assumed similarity coefficients as a function of communal values in Study 5. At each level of communal values, the pale curved lines show the $95 \%$ confidence interval around the estimated simple slopes for assumed similarity. 
moderated the effects of both normative and distinctive self-ratings $(\beta \mathrm{s}=.403$ and .105, SEs $=.010$ and $.008, p s<.001)$. Simple effects analyses showed that liked-other ratings were positively related to normative and distinctive self-ratings $(\beta \mathrm{s}=.621$ and .204$, SEs $=.011$ and $.011, p s<.001)$, whereas disliked-other ratings were negatively related to normative self-ratings $(\beta=$ $-.184, S E=.016, p<.001)$ and unrelated to distinctive selfratings $(\beta=-.004, S E=.013)$. Finally, greater communal values predicted greater distinctive similarity $(\beta=.031, S E=.009, p=$ $.001)$, and the Communal Values $\times$ Target interaction predicted normative similarity $(\beta=.032, S E=.010, p<.01)$. Simple effects analyses showed that greater communal values predicted greater normative similarity with liked others $(\beta=.052, S E=$ $.012, p<.001)$, but not disliked others $(\beta=-.010, S E=.016)$.

Mediated moderation. If people with strong communal values express favorable views of the self and of others with whom they are interconnected, then that could explain the effects of communal values on assumed similarity. To test this possibility, we tested whether attribute desirability mediated communal values' moderating effects on self-other similarity. There are two routes by which such mediated moderation might occur (Muller, Judd, \& Yzerbyt, 2005). One route is (1a) people in general describe themselves favorably and (1b) people with strong communal values describe others with whom they are connected more favorably than do people with weak communal values. A second route is (2a) people generally describe others with whom they are connected favorably and (2b) people with strong communal values describe themselves more favorably than do people with weak communal values.

We tested for mediated moderation in each of the studies for which we had information about attribute desirability (i.e., Studies 2-5). We defined trait desirability as follows: as a trait's average desirability rating in the two normative samples in Study 2 (see Study 2 Methods); as an effect-coded variable (undesirable $=-1$, desirable $=+1$ ) in Studies 3 and 4; and as each participant's idiosyncratic ratings of perceived trait desirability in Study 5. For simplicity, we are reporting all of the results here rather than in each study separately.
To test Condition 1a, we regressed trait desirability on selfratings. To test condition $2 \mathrm{a}$, we regressed other ratings on trait desirability while controlling for self-ratings. Table 2 Lines 1-2 show the results: In all studies, people made favorable ratings of both the self (Condition 1a) and others (Condition 2a). Therefore, in each study mediated moderation could occur if either Condition $1 \mathrm{~b}$ or Condition $2 \mathrm{~b}$ was met.

To test Condition $1 \mathrm{~b}$, we regressed other ratings on the Communal Values $\times$ Trait Desirability interaction, and to test Condition $2 b$, we regressed trait desirability on the Communal Values $X$ Self-Ratings interaction (while controlling for the other predictors in the model). Table 2 Lines 3-4 show the results: Condition $1 b$ (stronger communal values predicting more favorable descriptions of others) was met in Studies 2 and 3, and Condition 2b (stronger communal values predicting more favorable self-descriptions) was met in Studies 2, 3, and 5. Therefore, the conditions necessary for mediated moderation existed in Studies 2, 3, and 5, but not in Study 4

The two lines at the bottom of Table 2 show the moderating effect of communal values on assumed similarity before and after controlling for the effects of trait desirability. Controlling for desirability did reduce the moderating effect of communal values in Studies 2, 3, and 5; even so, the effect of communal values remained strong in all four studies. In summary, desirability did not mediate the moderating effect of communal values on selfother similarity in Study 4, and partially mediated the moderating effects of communal values in Studies 2, 3, and 5.

\section{Discussion}

Study 5 contributed to our understanding of the effects of communal values on assumed similarity with specific, known others. In addition to predicting greater distinctive similarity, communal values predicted describing both the self and liked (but not disliked) others in normative terms, which resulted in greater overall similarity with liked (but not disliked) others. Analyzing the role of trait desirability showed that people with stronger communal values tended to describe themselves and others in

Table 2

Conditions for Demonstrating That Trait Desirability Mediates the Moderating Effects of Communal Values on Assumed Similarity

\begin{tabular}{|c|c|c|c|c|c|c|c|c|c|c|}
\hline \multirow[b]{3}{*}{ Condition being tested } & \multirow[b]{3}{*}{ Predictor } & \multirow[b]{3}{*}{ Outcome } & \multicolumn{8}{|c|}{ Study/Type of target } \\
\hline & & & \multicolumn{2}{|c|}{$\begin{array}{l}\text { Study } 2 / \\
\text { Partner }\end{array}$} & \multicolumn{2}{|c|}{$\begin{array}{l}\text { Study } 3 / \\
\text { Ingroup }\end{array}$} & \multicolumn{2}{|c|}{$\begin{array}{l}\text { Study 4/ } \\
\text { Ingroup }\end{array}$} & \multicolumn{2}{|c|}{$\begin{array}{l}\text { Study } 5 / \\
\text { Liked others }\end{array}$} \\
\hline & & & $\beta$ & $S E$ & $\beta$ & $S E$ & $\beta$ & $S E$ & $\beta$ & $S E$ \\
\hline 1a & Self-ratings & Desirability & $.439^{* * *}$ & .010 & $.441^{* * *}$ & .014 & $.510^{* *}$ & .012 & $.719^{\text {*** }}$ & .013 \\
\hline $2 \mathrm{a}$ & Trait Desirability & Other-ratings & $.393^{* *}$ & .012 & $.144^{* * *}$ & .007 & $.065^{* *}$ & .011 & $.516^{* * *}$ & .014 \\
\hline $1 \mathrm{~b}$ & Communal Values $\times$ Desirability & Other-ratings & $.052^{* * *}$ & .013 & $.081^{* * *}$ & .019 & .039 & .028 & .004 & .014 \\
\hline $2 b$ & $\begin{array}{l}\text { Communal Values } \times \text { Self- } \\
\text { Ratings }\end{array}$ & Desirability & $.038^{* *}$ & .010 & $.047^{* *}$ & .012 & .017 & .020 & $.078^{* *}$ & .014 \\
\hline Moderating effect (unmediated) & $\begin{array}{l}\text { Communal Values } \times \text { Self- } \\
\text { Ratings }\end{array}$ & Other-ratings & $.085^{* *}$ & .013 & $.083^{* * *}$ & .017 & $.092^{* *}$ & .028 & $.080^{* * *}$ & .014 \\
\hline Moderating effect (residual) & $\begin{array}{l}\text { Communal Values } \times \text { Self- } \\
\text { Ratings }\end{array}$ & Other-ratings & $.049^{* *}$ & .012 & $.038^{*}$ & .014 & $.076^{*}$ & .026 & $.037^{*}$ & .012 \\
\hline
\end{tabular}

Note. "Other ratings" were partner ratings in Study 2, ingroup ratings in Studies 3 and 4, and liked-other ratings in Study 5. Because it did not influence the pattern of results, we did not distinguish between participants with and without partners in Study 2 or between Asian and American participants in Studies 3 and 4 .

${ }^{*} p<.01 .{ }^{* *} p \leq .001$. 
relatively favorable terms, but this tendency was inconsistent and, at most, could only partly explain the influence of communal values on assumed similarity.

\section{General Discussion}

We designed the present studies to explore the effects of interpersonal values on assumed similarity as well as potential mediators of and limits on those effects. In the following discussion, we focus on the effects of communal values but also mention a couple of noteworthy general findings involving assumed similarity and a couple of intriguing effects of culture.

\section{General Findings}

In general, people assumed that others shared their traits. Although self-other similarity was largely attributable to the normative component of self-ratings, even after controlling for the normativeness of self-ratings, the effect of the distinctive component of self-ratings on other ratings remained strong and robust. The one exception to the preceding statements is that people generally assumed dissimilarity with disliked others. This is not surprising; decades of research confirm that people perceive themselves as more similar to liked others than disliked others (Montoya et al., 2008). However, our research does suggest the importance of distinguishing normative and distinctive similarity (a distinction neglected in prior research). Specifically, we found that ratings of disliked others were negatively related to normative-but not distinctive-self-ratings. When considering disliked others, normative dissimilarity may be particularly appealing because it frames disliked others as isolated not only from the self but also from the larger community of good normal people to which the self belongs.

\section{Effects of Communal Values}

Our key hypothesis was that, compared with people with weak communal values, people with strong communal values would be more likely to assume they were similar to others with whom they were or would feel comfortable being interconnected. As hypothesized, stronger communal values predicted greater assumed similarity when predicting other students' presidential candidate choices or personality attributes. The effects of communal values were observed across different countries (India, Korea, and United States), different targets (romantic partners, liked others, ingroup members), and different traits, and remained significant even when controlling for self-esteem and national identification.

We explored several mechanisms by which communal values might influence similarity. One possibility is that people who value communion rely on a desirability heuristic-essentially, "If the attribute is desirable, then it applies to me and people connected to me." This simple heuristic (which only requires judging whether or not the attribute in question is desirable) is sufficient to generate assumed similarity between the self and others. Our results showed that, compared with people with weak communal values, people with strong communal values did describe themselves and others with whom they felt interconnected in more favorable terms. However, the results were inconsistent across studies and collectively indicated that rosy views of the self and others could only partially explain the effect of communal values on assumed similarity.

A second mechanism by which communal values might influence similarity is that people who value communion use a normativeness heuristic-essentially, "If the attribute is normal, then it applies to me and people connected to me." This simple heuristic (which only requires judging whether or not the attribute in question is common) is sufficient to generate assumed similarity between the self and others. To test this possibility, we decomposed overall similarity into normative similarity (describing self and others in normative terms) and distinctive similarity (describing self and others in the same distinctive terms). Our results showed that people with stronger communal values did use more normative terms to describe themselves and others with whom they were or felt comfortable being interconnected; consequently, communal values predicted normative similarity with each of these targets. These effects of communal values were observed across diverse countries and traits, and remained significant when controlling for self-esteem and national identification. However, people with stronger communal values were not more apt to apply normative terms to (and thus were not more normatively similar to) outgroups in Study 4 or disliked individuals in Study 5. In sum, people with stronger communal values were placed into the category of people with normal traits themselves and people with whom they were or felt comfortable being interconnected, but excluded from that category outgroup and disliked individuals.

Participants in Studies 3 and 4 also rated the typical member of their ingroup; the average (normative) self-rating by the members of that ingroup provides a criterion for evaluating the accuracy of these ingroup ratings. For example, a Korean student's rating of the typical Korean student on a trait can be compared with the average Korean student's actual self-rating on that trait. Using this criterion of accuracy, people with strong communal values-by virtue of describing their ingroup in relatively normative termsdescribed their ingroup relatively accurately. Furthermore, because people with strong communal values also described the self in relatively normative terms, they tended to describe themselves in the way most ingroup members described themselves. In other words, when people who value communion assume they are similar to other members of their group, their assumption-to the extent that they actually are relatively normative members-is accurate.

Finally, communal values also predicted distinctive self-other similarity (describing the self and others in the same distinctive terms), and did so across a variety of countries, attributes, and targets. Specifically, in Study 1, communal values predicted higher false consensus for presidential preferences (even after controlling for actual consensus estimates), and in Studies 2-5, communal values predicted distinctive trait similarity with liked and ingroup others (even after controlling for the normativeness of selfratings). However, communal values were either unrelated or negatively related to distinctive similarity with disliked and outgroup others.

In our introduction, we noted that different types of similarity convey different meanings. Being similarly desirable conveys "you and I are similarly worthy of esteem." Being similarly normative conveys "you and I are similarly normal and appropriate." Being similarly distinctive conveys "you and I are similarly unique." Communal values predicted all three sources of similar- 
ity. People with strong communal values assumed that they were similar to others with whom they were interconnected not only by virtue of being socially desirable and socially normative but also by virtue of sharing qualities that conferred a distinct identity; in essence, they assumed "we are good people and appropriate members of our group, but also uniquely us."

Summary and implications. The results confirmed our hypotheses about communal values. First, people who valued communion were more likely to assume that their friends, romantic partners, and peers shared their attitudes and traits. To the extent that people who value communion tend to describe themselves as typical or normative, such assumptions may be accurate; however, communal people also assumed greater similarity or consensus for their attitudes and traits than was warranted based on sample norms. More generally, the effects of communal values on assumed similarity were partly due to describing the self and others connected to the self as normal and desirable, but the effect of communal values on assumed similarity remained robust even after controlling for normativeness and desirability.

Second, the scope of communion was limited: Stronger communal values did not predict greater similarity with disliked and outgroup others. In this regard, our results generally support the "weak version" of the hypothesis; however, the negative association between communal values and distinctive self-outgroup similarity in Study 4 provides some support for the "strong version" of the hypothesis - that is, people who value communion more will assume less similarity with people with whom they are not interconnected.

Either way, it appears that people who value communion wish to be congruent with others, but not indiscriminately. One reason for their selectively is evident in the CSIV items that have been empirically found to have strong positive loadings on the communal dimension; examples of such items are "it is important that... they come to me with their problems" and "it is important that ... they support me when I am having problems." In other words, people who value communion want to give, but they also want to receive. Such "reciprocal altruism" is best sustained within bounded groups in which members share and enforce expectations for cooperation or know each other and each other's reputations.

Our results suggest additional hypotheses regarding how communal values might influence reactions to ingroup and outgroup members. For example, intergroup contact generally promotes assumed similarity and positive attitudes toward outgroup individuals, presumably in part by helping people to reframe outgroup individuals as "like me" (Stathi \& Crisp, 2008). If people with stronger communal values draw sharper boundaries between ingroup and outgroup members, then they may show greater increases in assumed similarity and positive attitudes toward outgroup individuals as those boundaries relax following intergroup contact. As another example, people generally express more dislike for a person who does not share their attitudes if that person is an ingroup member rather than an outgroup member (Chen \& Kenrick, 2002). This effect may be stronger for people with stronger communal values for two related reasons: (a) They are more likely to presume agreement among ingroup members and (b) they may experience dissent as an uncommunal action or "communal transgression," and people with stronger communal values have been shown to evaluate such transgressions more harshly (Kammrath \& Scholer, 2011).

\section{Cross-Cultural Differences}

Although cross-cultural differences were not the focus of our research, two such findings merit further discussion. First, the normativeness of self-ratings was greater in Korea than in America. Many studies suggest that East Asians more than Americans want to fit in, try to fit in, and focus on how they fit in with others; conversely, Americans more than East Asians want to stand out, try to stand out, and focus on how they stand out (Kim \& Markus, 1999; Markus \& Kitayama, 1991). One way to fit in is to have personality traits like those of your peers; one way to stand out is to have traits unlike those of your peers. Therefore, it is understandable why Koreans more than Americans might describe themselves as similar to each other.

Second, most studies find self-ingroup similarity exceeds selfoutgroup similarity (Robbins \& Krueger, 2005). Although we found that pattern in Asia, we found the opposite pattern in America. Therefore, we suspect many American students did not actually experience American students as an ingroup and foreign students as an outgroup. For example, some Americans may have conceptualized all targets as members of a larger ingroup (Gaertner, Mann, Murrell, \& Dovidio, 1989), such as fellow college students. Consistent with this possibility, whereas ingroup-versusoutgroup moderated the effect of communal values on assumed similarity in Asia ( $t \mathrm{~s}$ in Korea and India $=2.23$ and 3.25), the moderating effect of ingroup-versus-outgroup was weaker and not statistically significant in America ( $t$ s in Studies 3 and $4=1.56$ and 0.87$)$.

Other studies also suggest that the ingroup-outgroup distinction is more influential in Asia than America, and perhaps generally more salient in cultures that emphasize interdependence over independence (Heine \& Ruby, 2010). For example, compared with people from individualistic cultures, people from cultures that emphasize group-based collectivism tend to be more helpful and cooperative with ingroup members but less helpful and cooperative with outgroup members (Knafo, Schwartz, \& Levine, 2009; Triandis, 1989; Yamagishi \& Yamagishi, 1994). Of particular relevance to the present findings, several studies have found the influence of the ingroup-outgroup distinction on social cognition to be greater among Asians than among European Americans (Iyengar, Lepper, \& Ross, 1999).

However, Americans' insensitivity to ingroup-outgroup distinctions cannot explain why they described themselves as more similar to Asians. Another factor driving that finding was that American students expressed relatively negative stereotypes of American students and positive stereotypes of Asian students (e.g., regressing other ratings on trait desirability clearly showed that Americans described Asians more favorably than Americans; $t$ s in Studies 3 and $4=-7.68$ and -20.30 ). Because American students described their own personalities very favorably ( $t$ s in Studies 3 and $4=26.99$ and 28.41), they apparently regarded themselves to be unusually desirable examples of an American student, and controlling for desirability reduced or eliminated the tendency for Americans to assume greater similarity with Asians than Americans $(\Delta t s$ in Studies 3 and $4=-4.32$ and -9.01 ).

\section{Limitations and Future Directions}

As noted in the previous section, one limitation is that we assumed participants would construe foreign students as outgroup 
members and compatriot students as ingroup members, but did not measure how participants actually defined their ingroups and outgroups. The terms ingroup and outgroup could be specified more clearly in future research by directly assessing respondents' perceptions of group membership or by experimentally manipulating the salience of group boundaries.

Another limitation is that that we studied exclusively university students and measured primarily self-other trait similarity. On the positive side, our sample was large $(N=1,709)$, and our traits were carefully selected to cover a comprehensive array of content while minimizing confounds between content and desirability. Nonetheless, research on other populations (e.g., less educated individuals) and other types of descriptors (e.g., abilities) is needed to delineate the generalizability of the phenomenon.

A related concern is that in the present research we relied on a particular measure of communal values - the CSIV. The CSIV was appealing for two reasons. First, in contrast to measures of group identification or relational-independent self-construal, its items do not directly ask respondents whether they overlap with or share an identity with others. Second, the CSIV distinguishes effects of communion from effects of agency. Measures of related constructs (including those used to predict self-other similarity in prior research) typically assess a mixture of high communion and low agency, as illustrated by items such as "I worry that I won't measure up to other people" (an Anxious Attachment item; Fraley, Waller, \& Brennan, 2000), "It is important to me to fit into the group I am with" (a Need to Belong item; Morrison \& Matthes, 2011), and "It is important to me that I respect the decisions made by my groups" (a Collectivism item; Triandis, 1996). Therefore, effects of such measures on assumed similarity may reflect communion, submission, or both (whereas our CSIV findings clearly suggest that what predicts assumed similarity is communion, not submission). Nonetheless, any one measure is limited. For example, the CSIV asks about what matters to respondents when with others in general, but different types of relationships entail different types of communal binds and bounds. In particular, bonds experienced as voluntary and breakable (e.g., friendships if one lives in a large or fluid community) are likely to operate differently from bonds experienced involuntary or unbreakable (e.g., kinship or ethnic bonds, especially within collectivistic communities).

A more general limitation is that we did not investigate in the present research the mechanism by which communal values moderated distinctive self-other similarity. In general, three causal paths can explain self-other similarity: Representations of the self shape representations of others, representations of others shape representations of the self, and generic person representations (prototypes) shape representations of both self and others. Communal values could moderate self-other similarity by moderating any combination of these causal paths. Also unclear is to what extent the mechanism should be framed in motivational terms (e.g., communal people want to or feel better if they conceptualize themselves and selected others as similar) or nonmotivational terms (e.g., communal people have beliefs about or cognitive representations of self and others that result in overlapping descriptions). Of course, comparing-indeed, even distinguishing between-motivational and cognitive explanations is notoriously difficult (Tetlock \& Levi, 1982); for example, reinforcing thoughts soon become habits of thought. Nonetheless, further research that experimentally manipulates communal concerns may help elucidate the underlying mechanism.

\section{Conclusions and Speculations}

Compared with people with weak communal values, people with strong communal values are more open to sharing bonds of commonality and interdependence with others; however, because they feel obligated to care about and conform to the expectations of others with whom they are interconnected, people who value communion also put boundaries on their connections. Thus, in the present study people with strong communal values assumed strong similarities with people with whom they were or felt comfortable being interconnected (friends, real and imagined partners, ingroup members) but not with people with whom they were not (outgroup members and disliked others). In essence, in shaping our social worlds, strong communal values are a double-edged sword, severing some boundaries but sharpening others; consequently, people who value communion may experience a more differentiated social landscape than those who do not.

Interestingly, the effects of communal values mirror the effects of the neurotransmitter oxytocin. Oxytocin tends to promote favoritism toward and cooperation among ingroup members, but may promote mistrust and derogation toward outgroup members (De Dreu, Greer, Van Kleef, Shalvi, \& Handgraaf, 2011). More generally, oxytocin may intensify social experiences, including both embracing and rejecting social emotions (Kemp \& Guastella, 2011). The effects of oxytocin suggest that humans may be biologically predisposed to experience communion as focused on specific others or groups rather than as a general embrace of others regardless of how unfamiliar or strange those others might be.

Although communal attitudes and feelings may generally be focused on people with whom one has or wants some interconnection, there may be exceptions. For example, compassion seems to entail concern for and wanting to aide others regardless of their group membership and without expectation of reward or reciprocation. Indeed, Oveis, Horberg, and Keltner (2010) found that compassion predicted greater ratings of self-other similarity with people in need regardless of whether they were ingroup or outgroup members. However, even compassion seems restricted to people in need, and perhaps is inherently incompatible with experiencing the other person as doing well and as not in need.

The existence of individual differences in communal values itself suggests that communion has not always been an adaptive strategy, and whether it is adaptive may depend on the specifics of who we are and who are the other people with whom we can forge bonds (Buss, 2009). Regardless of their origin, our communal values can shape the way we conceptualize ourselves and others, which in turn can shape our social lives, including who we seek or avoid interdependencies with, who we welcome into or exclude from our scope of concern, and even who we deem to be as fully human as ourselves. What motivates our research is the hope that by recognizing and understanding these influences, we can use our communal dispositions to aide rather than hinder our ability to navigate an increasingly complex social world in which our interconnections span many boundaries. 


\section{References}

Bauer, D. J., \& Curran, P. J. (2005). Probing interactions in fixed and multilevel regression: Inferential and graphical techniques. Multivariate Behavioral Research, 40, 373-400. doi:10.1207/s15327906mbr4003_5

Biesanz, J. C. (2010). The social accuracy model of interpersonal perception: Assessing individual differences in perceptive and expressive accuracy. Multivariate Behavioral Research, 45, 853-885. doi:10.1080/ 00273171.2010.519262

Botwin, M. D., Buss, D. M., \& Shackelford, T. K. (1997). Personality and mate preference: Five factors in mate selection and marital satisfaction. Journal of Personality, 65, 107-136. doi:10.1111/j.1467-6494.1997 .tb00531.x

Buss, D. M. (2009). How can evolutionary psychology successfully explain personality and individual differences? Perspectives on Psychological Science, 4, 359-366. doi:10.1111/j.1745-6924.2009.01138.x

Byrne, D. (1971). The attraction paradigm. New York, NY: Academic Press.

Cadinu, M. R., \& Rothbart, M. (1996). Self-anchoring and differentiation processes in the minimal group setting. Journal of Personality and Social Psychology, 70, 661-677. doi:10.1037/0022-3514.70.4.661

Chen, F. F., \& Kenrick, D. T. (2002). Repulsion or attraction? Group membership and assumed attitude similarity. Journal of Personality and Social Psychology, 83, 111-125. doi:10.1037/0022-3514.83.1.111

Cialdini, R. B., Brown, S. L., Lewis, B. P., Luce, C., \& Neuberg, S. L. (1997). Reinterpreting the empathy-altruism relationship: When one into one equals oneness. Journal of Personality and Social Psychology, 73, 481-494. doi:10.1037/0022-3514.73.3.481

Coats, S., Smith, E. R., Claypool, H. M., \& Banner, M. J. (2000). Overlapping mental representations of self and in-group: Reaction time evidence and its relationship with explicit measures of group identification. Journal of Experimental Social Psychology, 36, 304-315. doi: 10.1006/jesp.1999.1416

Cronbach, L. J. (1955). Processes affecting scores on "understanding others" and "assumed similarity." Psychological Bulletin, 52, 177-193. doi: $10.1037 / \mathrm{h} 0044919$

Cross, S. E., Morris, M. L., \& Gore, J. S. (2002). Thinking about oneself and others: The relational-interdependent self-construal and social cognition. Journal of Personality and Social Psychology, 82, 399-418. doi:10.1037/0022-3514.82.3.399

De Dreu, C. K. W., Greer, L. L., Van Kleef, G. A., Shalvi, S., \& Handgraaf, M. J. J. (2011). Oxytocin promotes human ethnocentrism. Proceedings of the National Academy of Sciences of the United States of America, 108, 1262-1266. doi:10.1073/pnas.1015316108

DiDonato, T. E., Ullrich, J., \& Krueger, J. I. (2011). Social perception as induction and inference: An integrative model of intergroup differentiation, ingroup favoritism, and differential accuracy. Journal of Personality and Social Psychology, 100, 66-83. doi:10.1037/a0021051

Foa, U. G. (1961). Convergences in the analysis of the structure of interpersonal behavior. Psychological Review, 68, 341-353. doi: 10.1037/h0039638

Fournier, M. A., Moskowitz, D. S., \& Zuroff, D. C. (2011). Origins and applications of the interpersonal circumplex. In L. M. Horowitz \& S. Strack (Eds.), Handbook of interpersonal psychology (pp. 57-73). Hoboken, NJ: Wiley.

Fraley, R. C., Waller, N. G., \& Brennan, K. A. (2000). An item-response theory analysis of self-report measures of adult attachment. Journal of Personality and Social Psychology, 78, 350-365. doi:10.1037/00223514.78.2.350

Furr, R. M. (2008). A framework for profile similarity: Integrating similarity, normativeness, and distinctiveness. Journal of Personality, 76, 1267-1316. doi:10.1111/j.1467-6494.2008.00521.x

Gaertner, S. L., Mann, J., Murrell, A., \& Dovidio, J. F. (1989). Reducing intergroup bias: The benefits of recategorization. Journal of Personality and Social Psychology, 57, 239-249. doi:10.1037/0022-3514.57.2.239
Granberg, D., \& Brent, E. (1983). When prophecy bends: The preferenceexpectation link in U.S. presidential elections, 1952-1980. Journal of Personality and Social Psychology, 45, 477-491. doi:10.1037/00223514.45.3.477

Gray-Little, B., Williams, V. S. L., \& Hancock, T. D. (1997). An item response theory analysis of the Rosenberg Self-Esteem Scale. Personality and Social Psychology Bulletin, 23, 443-451. doi:10.1177/ 0146167297235001

Hampson, S. E. (1998). When is an inconsistency not an inconsistency? Trait reconciliation in personality description and impression formation. Journal of Personality and Social Psychology, 74, 102-117. doi: 10.1037/0022-3514.74.1.102

Hampson, S. E., Goldberg, L. R., \& John, O. P. (1987). Category-breadth and social-desirability values for 573 personality terms. European Journal of Personality, 1, 241-258. doi:10.1002/per.2410010405

Haslam, N., \& Bain, P. (2007). Humanizing the self: Moderators of the attribution of lesser humanness to others. Personality and Social Psychology Bulletin, 33, 57-68. doi:10.1177/0146167206293191

Heine, S. J., \& Ruby, M. B. (2010). Cultural psychology. Wiley Interdisciplinary Reviews: Cognitive Science, 1, 254-266.

Holmes, D. S. (1968). Dimensions of projection. Psychological Bulletin, 69, 248-268. doi:10.1037/h0025725

Holmes, D. S. (1978). Projection as a defense mechanism. Psychological Bulletin, 85, 677-688. doi:10.1037/0033-2909.85.4.677

Hopwood, C. J., Ansell, E. B., Pincus, A. L., Wright, A. G. C., Lukowitsky, M. R., \& Roche, M. J. (2011). The circumplex structure of interpersonal sensitivities. Journal of Personality, 79, 707-740. doi:10.1111/j.14676494.2011.00696.x

Horowitz, L. M., Wilson, K. R., Turan, B., Zolotsev, P., Constantino, M. J., \& Henderson, L. (2006). How interpersonal motives clarify the meaning of interpersonal behavior: A revised circumplex model Personality and Social Psychology Review, 10, 67-86. doi:10.1207/ s15327957pspr1001_4

Hubert, L., \& Arabie, P. (1987). Evaluating order hypotheses within proximity matrices. Psychological Bulletin, 102, 172-178. doi:10.1037/ 0033-2909.102.1.172

Human, L. J., \& Biesanz, J. C. (2011). Through the looking glass clearly: Accuracy and assumed similarity in well-adjusted individuals' first impressions. Journal of Personality and Social Psychology, 100, 349364. doi: $10.1037 / \mathrm{a} 0021850$

Iyengar, S. S., Lepper, M. R., \& Ross, L. (1999). Independence from whom? Interdependence with whom? Cultural perspectives on ingroups versus outgroups. In D. Miller \& D. Prentice (Eds.), Cultural divides: Understanding and overcoming group conflict (pp. 273-301). New York, NY: Russell Sage.

Kammrath, L. K., \& Scholer, A. A. (2011). The Pollyanna myth: How highly agreeable people judge positive and negative relational acts. Personality and Social Psychology Bulletin, 37, 1172-1184. doi: 10.1177/0146167211407641

Kemp, A. H., \& Guastella, A. J. (2011). The role of oxytocin in human affect: A novel hypothesis. Current Directions in Psychological Science, 20, 222-231. doi:10.1177/0963721411417547

Kenny, D. A. (1994). Interpersonal perception: A social relations analysis. New York, NY: Guilford Press.

Kim, H. S., \& Markus, H. R. (1999). Deviance or uniqueness, harmony or conformity? A cultural analysis. Journal of Personality and Social Psychology, 77, 785-800. doi:10.1037/0022-3514.77.4.785

Knafo, A., Schwartz, S. H., \& Levine, R. V. (2009). Helping strangers is lower in embedded cultures. Journal of Cross-Cultural Psychology, 40, 875-879. doi:10.1177/0022022109339211

Koestner, R., Losier, G. F., Worren, N. M., Baker, L., \& Vallerand, R. J. (1995). False consensus effects for the 1992 Canadian referendum. Canadian Journal of Behavioural Science, 27, 214-225. doi:10.1037/ 0008-400X.27.2.214 
Krivonos, P. D., Byrne, D., \& Friedrich, G. W. (1976). The effect of attitude similarity on task performance. Journal of Applied Social Psychology, 6, 307-313. doi:10.1111/j.1559-1816.1976.tb02406.x

Krueger, J. (2000). The projective perception of the social world: A building block of social comparison processes. In J. Suls \& L. Wheeler (Eds.), Handbook of social comparison: Theory and research (pp. 323351). New York, NY: Plenum/Kluwer. doi:10.1007/978-1-4615-42377_16

Krueger, J. (2007). From social projection to social behaviour. European Review of Social Psychology, 18, 1-35. doi:10.1080/10463280701284645

Krueger, J., \& Clement, R. W. (1994). The truly false consensus effect: An ineradicable and egocentric bias in social perception. Journal of Personality and Social Psychology, 67, 596-610. doi:10.1037/00223514.67.4.596

Kurzban, R., \& Leary, M. R. (2001). Evolutionary origins of stigmatization: The functions of social exclusion. Psychological Bulletin, 127, 187-208. doi:10.1037/0033-2909.127.2.187

Leary, T. (1957). Interpersonal diagnosis of personality. New York, NY: Ronald Press.

Leonardelli, G. J., Pickett, C. L., \& Brewer, M. B. (2010). Optimal distinctiveness theory: A framework for social identity, social cognition and intergroup relations. In M. Zanna \& J. Olson (Eds.), Advances in experimental social psychology (Vol. 43, pp. 65-115). New York, NY: Elsevier.

Locke, K. D. (2000). Circumplex scales of interpersonal values: Reliability, validity, and applicability to interpersonal problems and personality disorders. Journal of Personality Assessment, 75, 249-267. doi:10.1207/ S15327752JPA7502_6

Locke, K. D. (2003). Status and solidarity in social comparison: Agentic and communal values and vertical and horizontal directions. Journal of Personality and Social Psychology, 84, 619-631. doi:10.1037/00223514.84.3.619

Locke, K. D. (2008). Attachment styles and interpersonal approach and avoidance goals in everyday couple interactions. Personal Relationships, 15, 359-374. doi:10.1111/j.1475-6811.2008.00203.x

Locke, K. D. (2011). Circumplex measures of interpersonal constructs. In L. M. Horowitz \& S. Strack (Eds.), Handbook of interpersonal psychology (pp. 313-324). Hoboken, NJ: Wiley.

Locke, K. D., \& Christensen, L. (2007). Re-construing the relational self-construal and its relationship with self-consistency. Journal of Research in Personality, 41, 389-402. doi:10.1016/j.jrp.2006.04.005

Locke, K. D., \& Sadler, P. (2007). Self-efficacy, values, and complementarity in dyadic interactions: Integrating interpersonal and socialcognitive theory. Personality and Social Psychology Bulletin, 33, 94109. doi: $10.1177 / 0146167206293375$

Marks, G., \& Miller, N. (1987). Ten years of research on the false consensus effect: An empirical and theoretical review. Psychological Bulletin, 102, 72-90. doi:10.1037/0033-2909.102.1.72

Markus, H. R., \& Kitayama, S. (1991). Culture and the self: Implications for cognition, emotion, and motivation. Psychological Review, 98, 224253. doi:10.1037/0033-295X.98.2.224

Mikulincer, M., Orbach, I., \& Iavnieli, D. (1998). Adult attachment style and affect regulation: Strategic variations in subjective self-other similarity. Journal of Personality and Social Psychology, 75, 436-448. doi:10.1037/0022-3514.75.2.436

Miller, D. T., Turnbull, W., \& McFarland, C. (1988). Particularistic and universalistic evaluation in the social comparison process. Journal of Personality and Social Psychology, 55, 908-917. doi:10.1037/00223514.55.6.908

Montoya, R. M., Horton, R., \& Kirchner, J. (2008). Is actual similarity necessary for attraction? A meta-analysis of actual and perceived similarity. Journal of Social and Personal Relationships, 25, 889-922. doi: $10.1177 / 0265407508096700$

Morrison, K. R., \& Matthes, J. (2011). Socially motivated projection: Need to belong increases perceived consensus on important issues. European Journal of Social Psychology, 41, 707-719. doi:10.1002/ejsp.797

Morry, M. M. (2005). Relationship satisfaction as a predictor of similarity ratings: A test of the attraction-similarity hypothesis. Journal of Social and Personal Relationships, 22, 561-584. doi:10.1177/0265407505054524

Muller, D., Judd, C. M., \& Yzerbyt, V. Y. (2005). When moderation is mediated and mediation is moderated. Journal of Personality and Social Psychology, 89, 852-863. doi:10.1037/0022-3514.89.6.852

Murray, S. L., Holmes, J. G., Bellavia, G., Griffin, D. W., \& Dolderman, D. (2002). Kindred spirits? The benefits of egocentrism in close relationships. Journal of Personality and Social Psychology, 82, 563-581. doi:10.1037/0022-3514.82.4.563

Norman, W. T. (1967). 2800 personality trait descriptors: Normative operating characteristics for a university population. Ann Arbor: University of Michigan.

Orbell, J., \& Dawes, R. M. (1991). A "cognitive miser" theory of cooperators' advantage. American Political Science Review, 85, 515-528. doi: $10.2307 / 1963172$

Otten, S. (2002). "Me" and "us" or "us" and "them"? The self as heuristic for defining novel ingroups. In W. Stroebe \& M. Hewstone (Eds.), European review of social psychology (Vol. 13, pp. 1-33). New York, NY: Psychology Press.

Otten, S., \& Wentura, D. (2001). Self-anchoring and in-group favoritism: An individual profiles analysis. Journal of Experimental Social Psychology, 37, 525-532. doi:10.1006/jesp.2001.1479

Oveis, C., Horberg, E. J., \& Keltner, D. (2010). Compassion, pride, and social intuitions of self-other similarity. Journal of Personality and Social Psychology, 98, 618-630. doi:10.1037/a0017628

Preacher, K. J., Curran, P. J., \& Bauer, D. J. (2006). Computational tools for probing interaction effects in multiple linear regression, multileve modeling, and latent curve analysis. Journal of Educational and Behavioral Statistics, 31, 437-448. doi:10.3102/10769986031004437

Ready, R. E., Clark, L. A., Watson, D., \& Westerhouse, K. (2000). Selfand peer-reported personality: Agreement, trait ratability, and the "selfbased heuristic.". Journal of Research in Personality, 34, 208-224. doi:10.1006/jrpe.1999.2280

Riketta, M. (2005). Cognitive differentiation between self, ingroup, and outgroup: The roles of identification and perceived intergroup conflict. European Journal of Social Psychology, 35, 97-106. doi:10.1002/ ejsp.234

Riketta, M., \& Sacramento, C. (2008). "They cooperate with us, so they are like me": Perceived intergroup relationship moderates projection from self to outgroups. Group Processes and Intergroup Relations, 11, 115131. doi: $10.1177 / 1368430207084849$

Robbins, J. M., \& Krueger, J. I. (2005). Social projection to ingroups and outgroups: A review and meta-analysis. Personality and Social Psychology Review, 9, 32-47. doi:10.1207/s15327957pspr0901_3

Rosenberg, M. (1965). Society and the adolescent self-image. Princeton, NJ: Princeton University Press.

Ross, L., Greene, D., \& House, P. (1977). The "false consensus effect": An egocentric bias in social perception and attribution processes. Journal of Experimental Social Psychology, 13, 279-301. doi:10.1016/00221031(77)90049-X

Selfhout, M., Denissen, J. J. A., Branje, S., \& Meeus, W. (2009). In the eye of the beholder: Perceived, actual, and peer-rated similarity in personality, communication, and friendship intensity during the acquaintanceship process. Journal of Personality and Social Psychology, 96, 11521165. doi:10.1037/a0014468

Sherman, S. J., Chassin, L., Presson, C. C., \& Agostinelli, G. (1984). The role of the evaluation and similarity principles in the false consensus effect. Journal of Personality and Social Psychology, 47, 1244-1262. doi:10.1037/0022-3514.47.6.1244

Stanovich, K. E., \& West, R. F. (1998). Individual differences in rationa 
thought. Journal of Experimental Psychology: General, 127, 161-188. doi:10.1037/0096-3445.127.2.161

Stathi, S., \& Crisp, R. J. (2008). Imagining intergroup contact promotes projection to outgroups. Journal of Experimental Social Psychology, 44, 943-957. doi:10.1016/j.jesp.2008.02.003

Taylor, S. E., \& Brown, J. D. (1988). Illusion and well-being: A social psychological perspective on mental health. Psychological Bulletin, 103, 193-210. doi:10.1037/0033-2909.103.2.193

Tetlock, P. E., \& Levi, A. (1982). Attribution bias: On the inconclusiveness of the cognition-motivation debate. Journal of Experimental Social Psychology, 18, 68-88. doi:10.1016/0022-1031(82)90082-8

Toma, C., Yzerbyt, V., \& Corneille, O. (2010). Anticipated cooperation vs. competition moderates interpersonal projection. Journal of Experimental Social Psychology, 46, 375-381. doi:10.1016/j.jesp.2009.11.005

Tracey, T. J. G. (1997). RANDALL: A Microsoft FORTRAN program for a randomization test of hypothesized order relations. Educational and Psychological Measurement, 57, 164-168. doi:10.1177/ 0013164497057001012

Tracey, T. J. G. (2000). Analysis of circumplex models. In H. E. A. Tinsley $\&$ S. D. Brown (Eds.), Handbook of applied multivariate statistics and mathematical modeling (pp. 641-664). San Diego, CA: Academic Press. doi:10.1016/B978-012691360-6/50023-9
Triandis, H. C. (1989). The self and social behavior in differing cultural contexts. Psychological Review, 96, 506-520. doi:10.1037/0033295X.96.3.506

Triandis, H. C. (1996). The psychological measurement of cultural syndromes. American Psychologist, 51, 407-415. doi:10.1037/0003066X.51.4.407

Weller, J. A., \& Watson, D. (2009). Friend or foe? Differential use of the self-based heuristic as a function of relationship satisfaction. Journal of Personality, 77, 731-760. doi:10.1111/j.1467-6494.2009.00563.x

Wiggins, J. S. (1979). A psychological taxonomy of trait-descriptive terms The interpersonal domain. Journal of Personality and Social Psychology, 37, 395-412. doi:10.1037/0022-3514.37.3.395

Yamagishi, T., \& Yamagishi, M. (1994). Trust and commitment in the United States and Japan. Motivation and Emotion, 18, 129-166. doi: 10.1007/BF02249397
Received November 28, 2011

Revision received April 5, 2012 Accepted June 25, 2012 